NBER WORKING PAPER SERIES

\title{
EVIDENCE ON THE CHARACTERISTICS \\ OF CROSS SECTIONAL VARIATION \\ IN STOCK RETURNS
}

Kent Daniel

Sheridan Titman

Working Paper 5604

\author{
NATIONAL BUREAU OF ECONOMIC RESEARCH \\ 1050 Massachusetts Avenue \\ Cambridge, MA 02138 \\ June 1996
}

We thank participants of seminars at Dartmouth, Harvard Business School, HKUST, MIT, Northwestern, UCLA, University of Chicago, University of Illinois Urbana-Champaign, University of Michigan, USC, University of Texas, University of Tokyo, Wharton, and the February 1995 NBER Behavioral Finance Workshop, the PACAP, APFA and AFA conferences and Jonathan Berk, Mark Carhart, Randy Cohen, Douglas Diamond, Vijay Fafat, Wayne Ferson, Kenneth French, Steven Kaplan, Mark Kritzman, Josef Lakonishok, Craig MacKinlay, Alan Marcus, Chris Polk, Richard Roll, René Stulz, Robert Vishny and especially Eugene Fama for helpful discussions, comments and suggestions. Daniel thanks the Center for Research in Security Prices (CRSP) at the University of Chicago for research support. Titman gratefully acknowledges research support from the John L. Collins, S.J. Chair in International Finance. We are, of course, responsible for any errors. This paper is part of NBER's research program in Corporate Finance. Any opinions expressed are those of the authors and not those of the National Bureau of Economic Research.

(C) 1996 by Kent Daniel and Sheridan Titman. All rights reserved. Short sections of text, not to exceed two paragraphs, may be quoted without explicit permission provided that full credit, including $(\odot)$ notice, is given to the source. 
NBER Working Paper 5604

June 1996

\title{
EVIDENCE ON THE CHARACTERISTICS \\ OF CROSS SECTIONAL VARIATION \\ IN STOCK RETURNS
}

\begin{abstract}
Firm size and book-to-market ratios are both highly correlated with the returns of common stocks. Fama and French (1993) have argued that the association between these firm characteristics and their stock returns arises because size and book-to-market ratios are proxies for non-diversifiable factor risk. In contrast, the evidence in this paper indicates that the return premia on small capitalization and high book-to-market stocks does not arise because of the comovements of these stocks with pervasive factors. It is the firm characteristics and not the covariance structure of returns that explain the cross-sectional variation in stock returns.
\end{abstract}

Kent Daniel

Graduate School of Business

University of Chicago

1101 East 58th Street

Chicago, IL 60637
Sheridan Titman

Finance Department

School of Management

Boston College

Chestnut Hill, MA 02167

and NBER 


\section{Introduction}

There is now considerable evidence that the cross-sectional pattern of stock returns can be explained by characteristics such as size, leverage, past returns, dividend-yield, earnings-to-price ratios and book-to-market ratios. ${ }^{1}$ Fama and French $(1992,1996)$ examine all of these variables simultaneously and conclude that, with the exception of the momentum strategy described by Jegadeesh and Titman (1993), the cross-sectional variation in expected returns can be explained by only two of these characteristics, size and book-to-market. Beta, the traditional CAPM measure of risk, explains almost none of the cross-sectional dispersion in expected returns once size is taken into account. ${ }^{2}$

There is considerable disagreement about the reason for the high discount rate assigned to small and high book-to-market firms. The traditional explanation for these observations, exposited by Fama and French $(1993,1996)$, is that the higher returns are compensation for higher systematic risk. Fama and French (1993) suggest that book-to-market and size are proxies for distress and that distressed firms may be more sensitive to certain business cycle factors, like changes in credit conditions, than firms that are financially less vulnerable. In addition, the duration of high growth firms' earnings should be somewhat longer than the duration of the earnings of low growth firms, therefore term structure shifts should affect the two groups of firms differently.

In contrast, Lakonishok, Shleifer, and Vishny (1994) (LSV) suggest that the high returns associated with high book-to-market (or value) stocks are generated by investors who incorrectly extrapolate the past earnings growth rates of firms. They suggest that investors are overly optimistic about firms which have done well in the past and are overly pessimistic about those which have done poorly. LSV also suggest that low book-to-market (or growth) stocks are more glamorous than value stocks and may thus attract naive investors who push up prices and lower the expected returns of these securities. ${ }^{3}$

\footnotetext{
${ }^{1}$ The size anomaly was documented by Banz (1981) and Keim (1983), leverage by Bhandari (1988), the past returns effect by DeBondt and Thaler (1985) and Jegadeesh and Titman (1993), the earningsto-price ratio by Basu (1983), the book-to-market effect by Stattman (1980) and Rosenberg, Reid, and Lanstein (1985).

${ }^{2}$ See also Jegadeesh (1992).

${ }^{3}$ There is also a third potential explanation: Kothari, Shanken, and Sloan (1995) suggest that selection-
} 
Fama and French (1993) provide several tests that suggest that a firm's book-to-market ratio and size are in fact proxies for the firm's loading on priced risk factors. First, they show that the prices of high book-to-market and small size stocks tend to move up and down together in a way that is suggestive of a common risk factor. Secondly, they find that the loadings on zero cost factor portfolios formed based on size (a small capitalization portfolio minus large capitalization portfolio they call SMB) and book-to-market ratios (a high book-to-market portfolio minus a low book-to-market portfolio they call HML) along with a value-weighted market portfolio (Mkt) explain the excess returns of a full set of book-to-market and size-sorted portfolios. ${ }^{4}$

While LSV do not dispute the possibility that there may be priced factors associated with value (or growth) stocks, they argue that the return premia associated with these factor portfolios are simply too large and their covariances with macro factors are just too low (and in some cases negative) to be considered compensation for systematic risk. ${ }^{5}$ LSV present compelling evidence to support their claim, however their results are not inconsistent with multi-factor models, such as Merton (1973) and Ross (1976), which allow for priced factors that are orthogonal to the overall market return. An explanation for these return anomalies, based for example on Merton (1973), would require that we find a priced factor that is orthogonal to the market, yet affects future investment opportunities.

While we would expect that it would be very difficult to verify that the returns associated with size and book-to-market portfolios do indeed satisfy the above condition, it is likely to bias problems in the construction of book-to-market portfolios could be another cause of the premium. However, recent work by Chan, Jegadeesh, and Lakonishok (1995) shows that the selection biases are not large. Further, Cohen and Polk (1995a) construct portfolios in a way that completely eliminates the COMPUSTAT selection bias and find similar evidence. Finally, Davis (1994) forms book-to-market sorted portfolios free of selection bias in the 1940-1963 period (out-of-sample relative to the Fama and French 1963-1992 sample period) and finds a book-to-market effect similar in magnitude to that found by Fama and French (1992).

${ }^{4}$ As further evidence, Fama and French (1993) show that Mkt, HML and SMB portfolios formed from one-half of the CRSP sample of stocks can explain the returns of portfolios formed with stocks from the other half. In addition, Fama and French (1995) show that the same return factors are present in a firm's earnings, and Cohen and Polk (1995a) show that portfolios formed based on individual firm's covariances with the SMB and HML factor exhibit the same premia as do the original size and book-to-market sorted portfolios.

${ }^{5}$ MacKinlay (1995) makes a similar argument: He calculates the statistical distribution of the ex-ante Sharpe-ratio of the mean-variance efficient portfolio from the returns of the Fama and French (1993) portfolios, and concludes that the likely value of the the Sharpe-ratio obtainable is "too-high" to be explained within the context of efficient-market theory. 
be equally difficult to verify that the returns do not satisfy this condition. To show that these returns are not a factor in the Merton sense requires that we show that the factor cannot explain the component of consumption growth which is orthogonal to the market return. Given the difficulties associated with linking observed risk premia on the overall market to macro variables like aggregate consumption, this could be difficult to demonstrate.

In summary, the existing literature does not directly dispute the supposition that the return premia of high book-to-market and small size stocks can be explained by a factor model; rather, the debate centers on whether the factors can possibly represent economically relevant aggregate risk. In contrast, this paper addresses the more fundamental question of whether the return patterns of characteristic-sorted portfolios are really consistent with a factor model at all. Specifically, we ask (1) whether there really are pervasive factors that are directly associated with size and book-to-market; and (2) whether there are risk premia associated with these factors. In other words, we directly test whether the high returns of high book-to-market and small size stocks can be attributed to their factor loadings.

Our results indicate that (1) there is no discernible separate risk factor associated with high or low book-to-market (characteristic) firms, and (2) there is no return premium associated with any of the three factors identified by Fama and French (1993), suggesting that the high returns related to these portfolios cannot be viewed as compensation for factor risk. To elaborate, we find that although high book-to-market stocks do covary strongly with other high bookto-market stocks, the covariances do not result from there being particular risks associated with distress, but rather reflect the fact that high book-to-market firms tend to have similar properties; e.g., they might be in related lines of business, might be in the same industries or from the same regions. Specifically, we find that while high book-to-market stocks do indeed covary with one another, their covariances were equally strong before the firms became distressed. To determine whether characteristics or covariances determine expected returns we investigate whether portfolios with similar characteristics, but different loadings on the Fama and French (1993) factors, have different returns. We find that the answer is no. Once we control for firm characteristics, expected returns do not appear to be positively related to the loadings on the market, HML or SMB factors. 
Our results are disturbing in that, like Fama and French (1992), they suggest that traditional measures of risk do not determine expected returns. In equilibrium asset pricing models the covariance structure of returns determine expected returns. Yet we find that variables that reliably predict the future covariance structure do not predict future returns. Our results indicate that high book-to-market stocks and stocks with low capitalizations have high average returns whether or not they have the return patterns (i.e., covariances) of other small and high book-tomarket stocks. Similarly, after controlling for size and book-to-market ratios, a common share that "acts like" a bond (i.e.,, has a low market beta) has the same expected return as other common shares with high market betas.

The paper is organized as follows: In Section 2 we re-examine the return characteristics of portfolios of stocks sorted on size and book-to-market, paying particular attention to seasonalities in these returns, something that is important in our later analysis. In Section 3 we present a simple, purely descriptive, return generating model which provides some structure to our discussion of the empirical evidence presented in Sections 4 and 5. The model also provides some insights about why the Fama and French (1993) tests might fail to reject the factor pricing model when the model is incorrect and why a factor analysis test, like the tests presented in Roll (1994), might falsely reject a factor pricing model. In Section 4 we present evidence on one feature of this model, that there is no additional factor risk associated with high book-tomarket firms. Then in Section 5 we perform a set of empirical tests on another implication of our descriptive model, showing that, after controlling for firm characteristics, estimated factor loadings do not explain returns. Section 6 concludes the paper.

\section{A Summary of the Return Patterns of Size and Book-to- Market Sorted Portfolios.}

In this section we re-examine the return patterns of size and book-to-market sorted portfolios. What we show is that there are important interactions between the size and book-to-market effects and that the return patterns are different in January and non-January months. As we later discuss, both of these observations play important roles in our research design.

Panel A of Table 1 presents the mean excess returns for the 25 size/book-to-market sorted 
portfolios from Fama and French (1993), over the period 63:07 to 93:12. ${ }^{6}$ These portfolios are based on unconditional sorts using NYSE breakpoints. Therefore, for example, the small/low book-to-market portfolio is that set of firms included on NYSE/AMEX or NASDAQ which have book-to-market ratios in the range of the lowest quintile of NYSE firms and market equity in the lowest quintile of NYSE firms. All returns presented here are of value-weighted portfolios which are rebalanced annually, and consequently the results should not be driven by bid-ask bounce. $^{7}$

Panel A illustrates the magnitude of the return differential across the portfolios. First, we see that the difference in returns between the high book-to-market quintiles and the low bookto-market quintile of the same size was more than $50 \mathrm{bp} /$ month over this period (except for the very largest firms, where the difference is only $19 \mathrm{bp} /$ month).$^{8}$ Across size quintiles, the premia for the smallest quintile of firms over the largest is $30-50 \mathrm{bp} / \mathrm{month}$, except for the low book-to-market quintile where the difference is only $1 \mathrm{bp} /$ month.

An analysis of these returns suggests that after controlling for book-to-market there is more of a large firm rather than a small firm anomaly. Although the returns are almost monotonic in size, there are no significant differences in the returns of the small and medium size firms within any of the book-to-market groupings. However, the largest quintile of firms do have significantly lower returns than the rest, with this being especially true for the high book-to-market stocks. ${ }^{9}$ One implication of this is that a simple linear or log-linear regression of returns on capitalization and book-to-market ratios will not adequately characterize observed stock returns. There are important interaction effects that would be ignored in such a specification. For this reason, we will continue our strategy of examining the return patterns of various characteristic-sorted portfolios.

It is also possible that a factor structure could be artificially induced because of a common

\footnotetext{
${ }^{6}$ We wish to thank Eugene Fama and Kenneth French for supplying the portfolio returns. The construction of these portfolios is described in detail in Fama and French (1993).

${ }^{7}$ It is important to note that these premia may seem small, particularly across size quintiles, relative to results presented in other studies. This is because of the value-weighting and the use of NYSE breakpoints.

${ }^{8}$ Interestingly, we also find that the market-betas for both small and large high BM stocks are lower than for the corresponding low BM stocks.

${ }^{9}$ The contrast between this and what has typically been found in other studies is due to our use of value-weighted portfolios. The very smallest firms do have larger returns, but these firms are not heavily weighted in these portfolios.
} 
January seasonal. For this reason, we separately analyze the returns of the size and book-tomarket sorted portfolios in January and non-January months. Panels B and C of Table 1 give the mean returns of the same 25 Fama and French portfolios, only now separated into January and non-January months. This table shows that the size effect is almost exclusively a January phenomena and that the book-to-market phenomena occurs mainly in January for the larger firms, while the medium size and smaller high book-to-market firms exhibit about a $3 \%$ return premium in January and another $3 \%$ premium over the other 11 months. For the largest quintile of firms, high book-to-market stocks exhibit the same $3 \%$ January premium over the returns of low book-to-market stocks, however, for these stocks, the difference between the high and low book-to-market portfolio returns has been negative in the other 11 months. ${ }^{10}$

\section{A Model of the Return Generating Process}

In this section we present three models which clarify the motivation for our empirical tests. These should be viewed as purely descriptive models that provide a concrete framework for describing some of the opposing views described in the introduction. The first model, which we consider our null hypothesis, is consistent with the views described by Fama and French (1993, 1994, 1996) where there exists a "distress" factor with a positive risk premium. The second model represents an alternative hypothesis in which the factor structure is stable over time, and expected returns are determined by a firm's loading on factors with time varying return premia. In the third model firm characteristics rather than factor loadings determine expected returns. Extant empirical evidence is consistent with all three models, but in Sections 4 and 5 we will present empirical evidence that is inconsistent with all but the characteristic-based model.

In addition to motivating our own research design, the models presented in this section illustrate some possible pitfalls associated with past studies that examine whether loadings on factor portfolios explain the returns on characteristic-based portfolios. First, we argue that empirical studies that form benchmarks based on principal components or any other form of factor analysis may falsely reject a linear factor pricing model which in fact properly prices

\footnotetext{
${ }^{10}$ Davis (1994) finds similar results. We note also that this is consistent with DeBondt and Thaler (1985), though they look at past returns rather than Book-to-Market ratios.
} 
all assets. These arguments apply to the recent study by Roll (1994), which shows that factor loadings from a principal components analysis fail to explain the book-to-market effect, as well as to earlier tests of the arbitrage pricing theory that used factor analysis. ${ }^{11}$ In addition, we argue that research designs which uses the returns of characteristic-based portfolios as independent variables may fail to reject a factor pricing model when the model is in fact incorrect. Such designs include Fama and French (1993), as well as Chan, Chen, and Hsieh (1985), Jagannathan and Wang (1996) and Chan and Chen (1991).

\subsection{Model 1: The null hypothesis}

Our null hypothesis is that returns are generated by the following factor structure:

$$
\tilde{r}_{i, t}=E\left[\tilde{r}_{i, t}\right]+\sum_{j=1}^{J} \beta_{i, j} \bar{f}_{j, t}+\theta_{i, t-1} \tilde{f}_{D, t}+\tilde{\epsilon}_{i, t} \quad \epsilon_{i, t} \sim \mathcal{N}\left(0, \sigma_{e i}^{2}\right), f_{j, t} \sim \mathcal{N}(0,1)
$$

where $\theta_{i, t-1}$ is firm i's loading on the distress factor, $\tilde{f}_{D, t}$ at time $t$. In this factor pricing model, expected returns are a linear function of all factor loadings:

$$
E_{t-1}\left[\tilde{r}_{i, t}\right]=r_{f, t}+\sum_{j=1}^{J} \beta_{i, j} \lambda_{j}+\theta_{i, t-1} \lambda_{D}
$$

Here, the book-to-market ratio of the firm proxies for $\theta_{i, t-1}$, the loading on the distress factor. The premium associated with this distress factor, $\lambda_{D}$, is positive, meaning that firms which load on this distress factor (i.e., high book-to-market firms) earn a positive risk premium.

It is also important to note that $\theta_{i, t-1}$ varyies over time as firms move in and out of distress. This means that an experiment in which one estimates the factors using a purely statistical factor analysis, and then determines whether the premia of the high book-to-market portfolio can be explained by the loadings on these factors, would give invalid results: since there is no group of firms that continually loads on the distress factor, the factor cannot be extracted with a purely statistical factor analysis. ${ }^{12}$

\footnotetext{
${ }^{11}$ These would include papers by Lehmann and Modest (1988) and Connor and Korajczyk (1988) which use size-sorted portfolios as independent variables, but form factors based on individual firm returns.

${ }^{12}$ However, if there were changing weight portfolios of distressed firms included as returns in the principal components stage, it would be possible to properly extract the distress factor.
} 


\subsection{Model 2: A Model with Time Varying Factor Risk Premia}

Our first alternative hypothesis is a model in which there is no separate distress factor and in which the covariance matrix of returns is stable over time. This means that factor loadings do not change as firms become distressed. However, since distressed firms on average have high loadings on factors which have had negative realizations in the past, it appears as if a distress factor exists. For example, following a string of negative realizations on the oil factor, a portfolio of high book-to-market firms will contain a large number of oil stocks. As econometricians, we would identify movements in the oil factor at this point as movements in the distress factor, when in fact they are movements in the "distressed" oil factor.

In Model 2, a factor's risk premium increases following a string of negative factor realizations. Since many of the firms in the high book-to-market portfolio load on the distressed factor, the high book-to-market portfolio will have higher expected returns. In the example from the last paragraph, a portfolio of high book-to-market firms would earn a high return because it contains many oil firms, which load on the "distressed" oil factor, which now has a high return premium.

More formally, we assume that a time-invariant, J-factor model describes the variancecovariance matrix of returns.

$$
\tilde{r}_{i, t}=E\left[\tilde{r}_{i, t}\right]+\sum_{j=1}^{J} \beta_{i, j} \tilde{f}_{j, t}+\tilde{\epsilon}_{i, t} \quad \epsilon_{i, t} \sim \mathcal{N}\left(0, \sigma_{e i}^{2}\right), f_{j, t} \sim \mathcal{N}(0,1)
$$

The difference between this equation and equation (1) is that there is no separate distress factor $\tilde{f}_{D}$. Furthermore, we assume that the remaining $\beta$ 's in this model are constant over time, so that the covariance structure does not change as firms move in and out of distress. Again, the factor structure describes expected returns:

$$
E\left[\tilde{r}_{i, t}\right]=r_{f, t}+\sum_{j=1}^{J} \beta_{i, j} \lambda_{j, t-1}
$$

Now, however, unlike in equation (2), the risk premia on the $J$ factors vary through time. Also, the changes in the premia are negatively correlated with the past performance of the firms loading on this factor. This means that when a factor experiences negative realizations, the firms that load on the factor become distressed (their book-to-market ratios increase) and their expected returns increase because the $\lambda$ associated with this factor increases. 
Finally, we again assume that there is an observable variable $\theta_{i, t}$ (i.e., the book-to-market ratio). $\theta$ obeys a slowly mean-reverting process and the innovations in $\theta$ are negatively correlated with past returns (so that distressed firms have high $\theta$ 's). This means that, across firms, $\theta$ should be correlated with the factor loading on the currently distressed factor. Therefore, if a portfolio of the stocks of high $\theta$ firms is assembled, the stocks are likely to be those which have high loadings on factors with (currently) high $\lambda$ 's. In other words, the high $\theta$ portfolio is successfully timing the factors. This characterization is similar to that proposed by Jagannathan and Wang (1996), who suggest that small firms have high average returns because they have high betas on the market when the expected return on the market is high. ${ }^{13}$

\subsection{Model 3: A Characteristic-Based Pricing Model}

In contrast to the factor pricing models presented in Sections 3.1 and 3.2, the characteristicbased model presented in this section assumes that high book-to-market stocks realize a return premium that is unrelated to the underlying covariance structure. This model is thus inconsistent with Merton (1973) or Ross (1976) in that it permits asymptotic arbitrage.

As in Model 2, covariances are stationary over time and can be described by a factor structure. ${ }^{14}$ Specifically, we again assume that a time-invariant, approximate J-factor structure describes the variance-covariance matrix of returns.

$$
\tilde{r}_{i, t}=E\left[\tilde{r}_{i, t}\right]+\sum_{j=1}^{J} \beta_{i, j} \tilde{f}_{j, t}+\tilde{\epsilon}_{i, t} \quad \epsilon_{i, t} \sim \mathcal{N}\left(0, \sigma_{e i}^{2}\right), f_{j, t} \sim \mathcal{N}(0,1)
$$

However, in contrast to the previous models, factor loadings do not describe expected returns. Instead, we assume expected returns are a function of the observable, slowly varying firm attribute $\tilde{\theta}_{i, t}$ :

$$
E\left[\tilde{r}_{i, t}\right]=a+b_{1} \cdot \tilde{\theta}_{i, t-1}
$$

As in Model 2, the innovations in $\theta$ are negatively correlated with the returns on the stock, but $\theta$ is not directly related to the loadings on the distressed factors. What is unique about Model 3

\footnotetext{
${ }^{13}$ However, the setting here is slightly different: In the Jagannathan and Wang (1996) setting, the loadings of the individual (small) firms on the market factor change through time, while in the model presented here, factor loadings are constant but the composition of the high book-to-market firms changes over time.

${ }^{14}$ Although we focus on the relation between book-to-market ratios and returns in this section, the analysis also applies to the relation between size and returns.
} 
is that firms exist which load on the distressed factors but which are not themselves distressed, and therefore have a low $\theta$ and commensurately low return (and vice-versa). If Model 3 is true then following a string of negative shocks to the oil factor there may be some stocks which, despite their high loadings on the oil factor, are still not distressed. Model 2 suggests these firms should still earn the distress premium, because they behave like other distressed firms. In contrast, Model 3 suggests their returns behavior does not matter: if they are not distressed they will not earn the premium. Note also that Model 3 implies that a clever investor can earn the book-to-market return premium without loading on any common factors.

\subsection{Empirical Implications of the Models}

The empirical evidence that Fama and French (1993) present can be summarized with two empirical facts: (1) the stocks in the high book-to-market portfolio strongly covary with one another; and (2) high book-to-market stocks have high returns. The conclusion conventionally drawn from this evidence is that the firms in the high book-to-market portfolio are all loading on a factor which has a high premium; this is indeed the intuition suggested by the first two models.

Models 2 and 3 illustrate why this conclusion need notfollow from the evidence. It is true that since the distressed firms covary with one another, on average these firms must load on the same factor, which we can call the distressed factor. Of course, a firm will become distressed when a factor on which it loads has a strong negative realization. Using Bayesian reasoning, it therefore follows that firms which are distressed will, on average, load on the same factor. In both Model 2 and 3 (the characteristic-based model), this is why distressed firms covary with one another, not because of the presence of a separate distress factor. One way to discriminate between Model 1 and Models 2 and 3 is to see whether the return standard deviation of a portfolio of stocks increase if they all simultaneously become distressed. If the factor structure is stable and there is no separate distress factor (i.e., if Model 1 is false), then the return standard deviation should stay approximately constant.

Model 3 also indicates these existing empirical observations do not necessarily imply that returns are determined by factor loadings. In the characteristic-based model, the high returns are earned by all distressed firms, whether they load on the distressed factor or not. Some firms 
may have become distressed by virtue of bad realizations on an idiosyncratic term rather than on a common factor. Models 1 and 2 predict that such firms should not exhibit a premium; however, if the characteristic-based model is correct they should.

In tests where the test portfolio returns are constructed from characteristic sorted portfolios (as in Fama and French (1993)), the factor will appear to be associated with a high premium: since the average firm in the distressed portfolio does load on this factor, a strong correlation will be found between distressed factor loadings and return premia. Hence, to discriminate between the models, a test method must be used which separates out the firms which are high book-to-market, but which do not behave like high book-to-market firms. This is what our test in Section 5 does.

The stability of the covariance matrix turns out to be quite important for testing the pricing aspect of the characteristics-based model. If the factor structure is reasonably stable, we can use past factor loadings to predict future loadings and determine whether it is characteristics or factor loadings which determine returns. However, if the covariance matrix is unstable, it will be difficult to determine how firms will behave in the future, and consequently to find, for example, value firms which behave more like growth firms.

\section{The Covariation of Stocks with Similar Characteristics}

The characteristics-pricing model described in Section 3.3 differs from our null hypothesis as presented in Section 3.1 in two important ways. First, the characteristics model has no "distress" factor; the common variation in high book-to-market stocks arises because stocks with similar factor loadings are likely to become distressed at the same time. Second, the model specifies that average returns are determined by characteristics like book-to-market and size rather than factor loadings.

The first aspect of the model is important because the common variation among value and growth stocks has been interpreted as evidence of a distress factor. This is based on the following reasoning: if you randomly select 1000 stocks and go long a dollar in each of these, and randomly select 1000 stocks and go short a dollar in each of these, the resulting portfolio will effectively net out the various sources of factor risk and you should end up with a portfolio with an extremely 
small return variance. Assuming that the residual standard deviation of the individual stocks is roughly $10 \% /$ month, then the standard deviation of this random portfolio's returns would be about $0.25 \% /$ month. Instead, the HML portfolio has a standard deviation of about $2.5 \% /$ month indicating that the portfolio is subject to considerable factor risk. Fama and French (1993) interpret this evidence in the following way:

... portfolios constructed to mimic risk factors related to size and $B E / M E$ capture strong common variation in returns, no matter what else is in the time series regression. This is evidence that size and book-to-market equity indeed proxy for sensitivity to common risk factors in stock returns.

In contrast, the characteristics model assumes that this common variation arises because the HML portfolio consists of "similar" firms that have similar factor loadings whether or not they are distressed. In other words, the return generating model is assumed to be reasonably stable, but firms with similar factor loadings are expected to be distressed at the same time.

\subsection{The Portfolio Returns}

In this section we examine how the risk characteristics of stocks change in the years leading up to their inclusion in the various characteristic portfolios. If Model 1 provides a good characterization of the data, then on average, the covariances between the stocks should be higher when they are in the high book-to-market portfolio than when they are not. However, under the specifications in Models 2 and 3, covariances are constant over time.

Following Fama and French (1993), we form six portfolios based on the intersection of the three book-to-market categories ( $H$ igh, Medium and $L$ ow) and two size categories (Small and $B$ ig). These portfolios are designated LS, MS, HS, LB, MB, and HB. In addition we form the two zero-investment portfolios $H M L$ ( $H$ igh-Minus-Low) and SMB (Small-Minus-Big), which Fama and French use to capture the book-to-market and size effect. ${ }^{15}$ We then calculate the pre-formation and post-formation return standard deviations, in each of the five years before and five years after the formation date, of hypothetical portfolios that have constant portfolio weights equal to the formation date weights of the eight portfolios described above. ${ }^{16}$

\footnotetext{
${ }^{15}$ Details about the construction of the set of portfolios is described in the Appendix.

${ }^{16}$ Note that this gives us slightly different returns over the period July: $t$ through June: $(t+1)$ than for the standard HML portfolio; we are holding the weights constant here so we are not generating buy-and-hold returns. Elsewhere in the paper we calculate true buy-and-hold returns.
} 
Before looking at pre- and post- formation date standard deviations we will examine the average returns of stocks included in the HML portfolios prior to the formation date. We calculate these average pre-formation returns for the entire set of formation dates from June 1963 through June 1990 (28 years), and plot these in Figure 1. We stop in 1990 because this is the last formation date for which six years of future return data is available. This figure shows that the pre-formation returns of the HML portfolio are strongly negative, supporting the contention of Fama and French that high book-to-market firms are distressed and that low book-to-market firms have performed well in the past. Another important feature of this plot is the large returns experienced in every January in the pre-formation period. Every pre-formation (average) return outside of January is negative and every average January return is positive. Note also that there is a large "step" in the returns in January of the formation year. This is because the portfolios are formed based on the book-to-market ratios at the end of the preceding year, as described earlier.

To determine how covariances change in the pre- and post- formation period we examine the pre- and post-formation return standard deviations of the eight portfolios. One difficulty with this analysis is that a considerable fraction of the firms in the HML portfolio are not traded five years before or five years after the portfolio formation date. For example, about half of the small growth stocks (L/S portfolio) do not have CRSP or COMPUSTAT data five years prior to their inclusion in the portfolio. Similarly, about $25 \%$ of the H/S firms do not have data five years subsequent to their inclusion. Therefore, to generate this table, we have also imposed the additional requirement that, for a firm to be included in the analysis, it must have returns reported on CRSP in June:(t-5) for the Backward Looking Analysis (where June:t is the formation date), and at June:(t+5) for the forward looking analysis. Without this restriction, the formation-year 5 and -5 portfolios would contain a substantially smaller number of firms than the lag 0 portfolios. ${ }^{17}$

These standard deviations are presented in Table 2. First, consider the leftmost column in Panel A, labeled with formation-year 5. The numbers in this column are the excess return standard deviations for the portfolio formed based on the characteristics five years in the future. For example, the portfolio's composition between July of 1963 and June of 1964 is based on

\footnotetext{
${ }^{17}$ We also generated the Table without imposing this requirement. The results do not change materially.
} 
firm sizes at the end of June 1968 and book-to-market ratios at the end of December of 1967. This column provides the standard deviation of the portfolios five years prior to their actual formation dates.

Because of data restrictions we investigate only the 63:07-89:06 period for the "Backward Looking" portfolios: reforming the formation-year 5 portfolio in 89:07 would require stock prices for June of 1994, which we do not currently have access to. For the "Forward Looking" Analysis in the right side of the Table we use the sample period from through 68:07-93:12 because bookto-market ratios are not available before December 1962 . We calculate the standard deviations of each of these 54 series (six lagged years times nine portfolios) for each lag and tabulate these in Panel $\mathrm{A}$ of Table 2. We see that the difference in the lags \pm 5 and lag 0 standard deviations is close to zero for all series except the HML, for which the standard deviations increase from 2.2 to 2.5. However, part of the increase in standard deviation for the HML portfolio arises because it exhibits a large January seasonal, as we saw in Figure 1. In Panel B of Table 2 we perform the same standard deviation calculation, only we now exclude all Januarys from the sample. There is still a slight increase in standard deviation in moving from formation-year 5 to 0 , (and a decrease in moving from formation-year -5 to 0 ) but this increase is only about $10 \%{ }^{18}$

In summary, the reason that high book-to-market stocks exhibit strong common variation is not because they load on a separate distress factor. If this were the case, this common variation would disappear when we look prior to and after the time when these firms are most distressed. We instead find that the common variation is present both five years before and after these firms are in the distress/growth portfolio. This suggests that the common variation is always present for the set of $\mathrm{H}$ and $\mathrm{L}$ firms, and is not a result of loading on a separate factor that is present only when they are in a distress/growth phase. ${ }^{19}$

\footnotetext{
${ }^{18}$ We note that the HML portfolio returns exhibit high standard deviations at -1 and -2 years. Recall that these portfolios are formed based on ex-post information that they will (on-average) experience large positive (for the $\mathrm{H}$ portfolios) or negative returns (for the $\mathrm{L}$ portfolios) in formation-years 1 and 2. Perhaps this contributes to the high standard deviations. Notice that there is no such effect for the formation-year -1 and -2 portfolios, which are formed based on ex-ante information.

${ }^{19}$ We considered the possibility that the returns standard deviations change very little because the book-to-market ratios of the six portfolios change very little. However, we calculate the average bookto-market ratio for the six portfolios in the table, and show that they do change significantly (these data are available upon request). In addition, we regressed the time series of returns in Panel A of Table 2 on the three Fama/French factor-mimicking portfolios. For the HML portfolio, the $\beta_{H M L}$ coefficient falls substantially in moving from 0 lags to either +5 or -5 . The coefficient is 0.46 for formation year 5 , and
} 


\section{Cross-Sectional Tests of the Factor Model}

If a factor pricing model is correct, then a high book-to-market stock with a low book-to-market factor loading should have a low average return. In contrast, if prices are based on characteristics rather than on factor loadings, then a high book-to-market stock should have a high expected return regardless of its loading. This Section presents tests of the two factor pricing models (Models 1 and 2) against the characteristic-based alternative (Model 3).

As discussed in Section 3.4, discriminating between these models requires portfolios that exhibit low correlation between their factor loadings and their characteristics (e.g., high bookto-market ratios but low loadings on the HML factor). In order to construct such portfolios we first form portfolios based on characteristics (size and book-to-market), and then sort each of these into sub-portfolios based on the firms' pre-formation factor loadings. In this respect, our analysis is very similar to the analysis in Fama and French (1992) and Jegadeesh (1992) who construct portfolios that exhibit independent variation in size and beta. As in these papers, we then analyze whether the returns for the sub-portfolios vary with the factor loading, as Models 1 and 2 predict they should.

\subsection{Construction of the Test Portfolios}

We first rank all NYSE firms by their book-to-market ratio at the end of year $t-1$ and their market capitalization (ME) at the end of June of year $t$, as described in the Appendix. We form $33.3 \%$ and $66.6 \%$ breakpoints for book-to-market and ME based on these rankings. Starting in July of year $t$, we then place all NYSE/AMEX and NASDAQ stocks into the three book-tomarket groups and the three size groups based on these breakpoints. The firms remain in these portfolios from July of year $t$ to June of year $t+1$.

The stocks in each of these nine portfolios are then placed into smaller portfolios, based on the stocks' expected future HML factor loading, using information that is ex-ante observable. The resulting sets of portfolios consist of stocks with approximately the same size and book-tomarket ratios but with different loadings on the book-to-market factor HML. These portfolios 0.36 for formation year -5 , versus a coefficient of approximately 1 at lag 0 . This demonstrates that the high standard deviation of the lead or lagged HML portfolio returns cannot be attributed to comovement with the current set of value/growth firms. 
allow us examine the extent to which average returns are generated by the factor loadings rather than the characteristics.

We use the stocks' pre-formation factor loadings as instruments for their future expected loadings. To estimate these, we regress each stock's returns on three pre-formation factor portfolios (described in the next paragraph) for the period -42 to -7 relative to the portfolio formation date. We did not use the month -6 to 0 observations to estimate these loadings because the factor portfolios are formed based on stock prices existing 6 months previously. This is illustrated in Figure 1. From this plot, it can be seen that returns are very negative up to $t=-6$, when the book-to-market ratios are calculated. However, the portfolio returns are large between $t=-6$ and $t=-1$. This "step function" in the return pattern would add noise to our factor loading estimates, so we exclude it from our estimation period.

The factor portfolios used to calculate the pre-formation factor loadings differ from the Fama and French factor portfolios in an important respect. The Fama and French factor portfolio weights change every year as firm size and book-to-market change. What we do is take the portfolio weights of the Fama and French factor portfolios at the end of June of year $t$ and apply these constant weights to returns from date -42 to -7 to calculate the returns of constant weight factor portfolios, as described in Section 4.1. Based on our hypothesis that the covariance matrix is stationary over time, factor loadings calculated from factor portfolios constructed in this way should provide much better predictions of the future covariance of firms with the HML factor. As our evidence in the last section indicates, covariances between stocks entering the high book-to-market portfolio seem relatively stable. ${ }^{20}$

Based on these ex-ante estimates of the factor loadings we then equally divide each of the nine book-to-market and size sorted portfolios into five value-weighted portfolios. Unfortunately, several of the 45 portfolios formed in this way have as few as 1 stock in them for the years between 1963 and 1973. As a result we must restrict our time-series tests to the 1973-1993 period; the number of stocks in each portfolio is almost always above 10, and is generally much higher than this after 1973.

\footnotetext{
${ }^{20} \mathrm{As}$ further evidence on this point, we also constructed portfolios by sorting stocks based on their covariances with past HML returns. The dispersion in post-formation factor loadings across portfolios formed in this way was substantially smaller than the dispersion in ex-post factor loadings of portfolios constructed in the manner described above.
} 


\subsection{Empirical Results}

Table 3 presents the mean excess returns for the 45 portfolios described in the previous section. As we move from column 1 to 5 in this table we are moving from portfolios with low ex-ante loadings on the HML factor to portfolios with high loadings. The table reveals no discernible relation between factor loadings and returns for the portfolios of smaller stocks but a relatively weak positive relation between the factor loadings and returns for the portfolios comprised of larger stocks; however, the difference between the average returns of first and fifth factor loading portfolios is only $0.07 \% /$ month. Moreover, it is possible that this weak positive relation occurs because, in sorting on the HML factor loading, we are picking up variation in the book-to-market ratio within the relatively broad categories.

We examine this possibility in Table 4 which provides the average book to market ratios and sizes of each of the 45 portfolios. The average book to market ratios and sizes reported for each portfolio are calculated relative to the median NYSE firm at each formation date. What we find is that across factor-loading portfolios, within any book-to-market/size grouping, there is some covariation between the average book-to-market ratio and the HML factor loading. And indeed, this pattern is strongest for the large firm $(S z=3)$ portfolios, which is also where we see the strongest positive relation between factor loadings and returns. ${ }^{21}$ This factor/characteristic covariation will decrease the power of our test to reject the factor model (Model 1) in favor of the characteristics model (Model 3), however we will see later that the test is still adequately powerful to reject the null hypothesis. The lack of a relation between the loadings and the returns could potentially reflect the fact that pre-formation betas are weak predictors of future (or post-formation) loadings. However, the results reported in Table 5 indicate that our method does in fact achieve considerable dispersion in the post-formation factor loadings. In Table 5, we report the results of regressing the post-formation excess returns for each of the 45 portfolios on an intercept and on the returns of the zero-investment $M k t$, HML and SMB portfolios.

We see in Table 5 that the HML coefficients are clearly different for the different book-to-

${ }^{21}$ Mean size is roughly constant across the factor loading portfolios. The only regular pattern is that the more extreme factor loading portfolios (portfolios 1 and 5) tend to be slightly smaller. This is probably because smaller stocks have higher return standard deviations, and therefore the $\hat{\beta}$ 's calculated for these firms are likely to be more extreme than for the larger firms. 
market groups, as they should be: we know that, unconditionally, book-to-market ratios and HML loadings should be highly correlated. But the important thing for us is that within a book-to-market/size grouping, the sort on the pre-formation HML factor loadings produces a monotonic ordering of the post-formation factor loadings. Moreover, there appears to be a highly significant difference between the loadings of the low and high factor-loading portfolios, something we shall verify shortly. ${ }^{22}$

We are especially interested in the estimated intercepts. Models 1 and 2 predict that the regression intercepts ( $\alpha$ 's) should be zero, while model 3 suggests that the mean returns of the portfolios should depend only on characteristics (size and book-to-market), and should be independent of variation in the factor loadings. Hence, Model 3 also predicts that the $\alpha$ 's of the low factor-loading portfolios should be positive and that those of the high-factor loading portfolios should be negative. The $\alpha$ 's reported in this table indicate that this is generally the case. Only one of the nine high loading portfolios (see column 5) has a positive $\alpha$ and only two of the low loading portfolios (see column 1) has a negative $\alpha$. Furthermore, the average $\alpha$ for factor loading portfolio 1 is $0.02 \%$ per month, and for factor loading portfolio 5 it is $-0.24 \% /$ month. The difference is $-0.26 \% /$ month. Recall that Table 3 showed that the difference in average returns for these portfolios was only $0.07 \% /$ month.

In Table 6 we formally test whether the $\alpha$ 's associated with the high and low factor loadings are significantly different from each other. To do this we calculate the returns to portfolios which, for each of the nine book-to-market and size groupings, invests one dollar in each of the factor loading portfolios 1 and 2 and sells one dollar in each of factor loading portfolios 4 and 5. We call these "characteristic-balanced" portfolios, since both the long and short positions in the portfolios are constructed to have approximately equal book-to-market ratios and capitalizations. Each of these nine zero cost portfolios are then combined to form one zero cost characteristic-balanced portfolio. ${ }^{23}$

The characteristic-based model predicts that the average return from these zero cost characteristic-

\footnotetext{
${ }^{22}$ We note that the dispersion in pre-formation factor-loadings is considerably greater. This is because the pre-formation factor loading dispersion is due to both measurement error effects and the actual variation in factor-loadings. The post-formation dispersion results almost exclusively from true variation in the loadings.

${ }^{23}$ We also constructed portfolios by investing one dollar in portfolio 1 and selling one dollar of portfolio 5 and obtained very similar results.
} 
balanced portfolios should be indistinguishable from zero. In addition, the characteristic-based model predicts that the estimated intercept from a regression of the returns of these zero cost portfolio on the Fama and French factor portfolios should be positive. In contrast, the factor pricing models described in models 1 and 2 predict that the average returns should differ from zero, but that the intercept from the factor model should be indistinguishable from zero.

The results reported in Table 6 reveals that all but one of the $\alpha$ 's from the time-series regressions of the nine individual characteristic-balanced portfolio returns on the factor returns are positive, and three of the nine have T-statistics above 2. Furthermore, the intercept for the regression of the returns of the combined characteristic-balanced portfolio on the factor portfolios is large, $0.354 \% /$ month or over $4 \% /$ year, and is statistically different from zero. ${ }^{24}$ In contrast, the mean return of this portfolio is only $-0.116 \%$ per month (T-Statistic of -0.60 ), which is only one-third of the size of the factor model intercept, and is insignificantly different from zero. These results are consistent with the characteristic-based pricing model and are inconsistent with the factor pricing models (Models 1 and 2).

\subsection{Sorting by Other Factor Loadings}

This section presents similar tests that allow us to determine whether the SMB and MKT factors are priced, after controlling for size and book-to-market characteristics. Table 7 presents the mean returns, coefficients on the SMB factor, the intercepts and associated T-statistics for a set of portfolios constructed in the manner described in the last section, except that now the nine portfolios are each sorted into quintiles based on the pre-formation SMB factor loadings, rather than on the HML factor loadings. It can be seen in the SMB betas that our sorting method is picking up dispersion in the SMB factor loadings within the size sorted portfolios.

The lower right panel of Table 7 provides the T-statistics for the regression of the characteristicbalanced portfolio returns on the three factors. Again, the characteristic-balanced portfolio returns are the differences in returns between the two lowest factor loading portfolios (in columns 1 and 2 of the upper panels) and the two highest factor loading portfolios (in columns 4 and 5),

\footnotetext{
${ }^{24}$ The intercept, $\alpha$, is the return of a portfolio which has $\beta$ 's of zero on all three factors, and which is constructed by buying $\$ 1$ of the single portfolio and selling quantities of the zero-investment factormimicking portfolios (Mkt, SMB and HML) which are equal to the regression coefficients shown at the bottom of Table 6 .
} 
i.e., the return on a zero cost portfolio where the long and short components have similar characteristics. First, the column giving the T-statistic on the intercept on the SMB factor shows that there is substantial negative loading on the SMB portfolios. Second, the characteristic-based model suggests that the intercepts should be positive, and indeed all but one of them are, though the T-statistics are not large. The last row of the last panel, headed "single portfolio," gives the coefficients and T-statistics for the regression of the sum of the characteristic-balanced portfolio returns on the three factors. Although the coefficient is large in magnitude, representing an excess return of more than $3 \%$ per year, it is only marginally significant.

The analysis presented in Table 8 is the same, only now we sort on the $M k t$ loadings. Again, the T-statistics for the characteristic-balanced portfolios indicate that the factor model is rejected in favor of the characteristic-based model. Also, since the mean return of the single characteristic-balanced portfolio is $0.095 \%$ /month ( $T$-statistic of 0.3 ), the data does not provide evidence against Model 3, and in support of the factor model. Strikingly, the mean return of this portfolio is positive even though the portfolios market beta is -0.54 . Here we again find that the characteristic matters and not the factor loading. In other words a stock earns the "stock" premium even if its return pattern is similar to that of a bond (i.e., it has a low $\beta_{M k t}$ ).

These results are similar to the results reported by Fama and French (1992) and Jegadeesh (1992) who show that, after controlling for size, there is a slightly negative relationship with beta. ${ }^{25}$ We also see from the last row of the Table that the three-factor model is rejected for this portfolio with a T-statistic of 2.2.

\subsection{Factor Loadings, Characteristics, Turnover and Past Returns}

The fact that there are stocks with similar capitalizations and book to market ratios but very different factor loadings deserves further analysis. We do not find this surprising, given that firms in very different industries can be very similar along these two dimensions. However, we would like to know if these differences in factor loadings are significantly related to either volume or returns in the recent past since there is evidence suggesting that momentum (Jegadeesh and Titman 1993) and liquidity (Amihud and Mendelson 1986) can be important predictors of stock

\footnotetext{
${ }^{25} \mathrm{Bear}$ in mind, though, that we are looking at the market coefficient in a multiple regression, whereas the two cited papers use a univariate regression.
} 
returns.

One possibility is that the low factor loading stocks are the less liquid stocks. (Perhaps, the factor loadings of the less liquid stocks are underestimated because their returns lag the returns of the more liquid stocks in the factor portfolios.) If this were the case, and if in addition there was a liquidity premium, then one might expect the lower expected returns associated with having a lower factor loading would be offset by the return premia associated with illiquidity.

Similarly, we might expect that the low factor loading stocks are those that did very poorly over the previous year and just recently entered the high book to market portfolio. However, this would bias our tests towards supporting the factor model since the momentum effect would lower the returns of these low loading stocks. In order to bias our results against the factor model the past years returns of the stocks must be negatively related to the factor loading.

To explore these possibilities we calculated the average turnover and the average return over the 12 pre-formation months for each of the 45 portfolios. These are tabulated in Tables 9 and 10. The findings reported in this table suggests that our lack of support for a factor model is not due to either momentum or liquidity. Indeed, the portfolios with the lowest factor loadings seem to have the highest turnover, suggesting that if liquidity does have an effect on returns, it would bias our results towards finding a relation between factor loadings and returns. In addition, there does not seem to be any noticeable relation between past returns and factor loadings.

\section{Conclusions}

The analysis in this paper demonstrates two things: First, we show that there is no evidence of a separate distress factor. Most of the comovement of high book-to-market stocks is not due to distressed stocks being exposed to a unique "distress" factor, but rather, because stocks with similar factor sensitivities tend to become distressed at the same time. Second, our evidence suggests that it is characteristics rather than factor loadings that determine expected returns. We show that factor loadings do not explain the high returns associated with small and high book-to-market stocks beyond the extent to which they act as proxies for these characteristics. Further, our results show that, with equities, the market beta has no explanatory power for returns even after controlling for size and book-to-market ratios. Although our analysis focused 
on the factor portfolios suggested by Fama and French (1993), we conjecture that factor loadings measured with respect to the various macro factors used by Chan, Chen, and Hsieh (1985), Chen, Roll, and Ross (1986) and Jagannathan and Wang (1996) will also fail to explain stock returns once characteristics are taken into account. These papers explain the returns of size and/or book-to-market-sorted portfolios and are thus subject to our criticism of the Fama and French (1993) analysis.

Some of our colleagues have argued that although we have shown that the Fama and French factors are inefficient, we have not refuted the more general claim that the size and book-tomarket effects can be explained by a factor model. ${ }^{26}$ This argument is based on the idea that the HML portfolio contains noise as well as factor risk. If this is true and if the book-to-market ratio is a very good proxy for the priced factor loading, then $\beta_{H M L}$ may provide almost no additional information on the true factor loading, after controlling for the book-to-market ratio. Under these assumptions, in sorting on factor loading as we do in Table 5, we are picking out variation in the measured $\beta_{H M L}$ 's which is not associated with variation in the priced factor loading, and hence we cannot expect returns to vary with $\beta_{H M L}$.

While we certainly cannot rule out the possibility that factor model can explain this data, we still find this argument unconvincing for several reasons. First, the argument suggests that if the models are estimated with less noisy factors, we are less likely to reject the factor model. However, more recent evidence suggest that this is not the case. Cohen and Polk (1995b) and Frankel and Lee (1995) show that refined measures of the book-to-market characteristic have. considerably more ability to predict future returns than the standard book-to-market ratio. More importantly, Cohen and Polk show that when they replicate our cross-sectional test (in Table 5) with their more efficient industry-adjusted HML factor, ${ }^{27}$ they find that the factor model is still rejected in favor of our characteristics model. ${ }^{28}$

\footnotetext{
${ }^{26}$ We thank Kenneth French for bringing this possibility to our attention.

${ }^{27}$ More efficient here means that it has a higher Sharpe ratio.

${ }^{28}$ Specifically,Cohen and Polk (1995b) calculate adjusted book-to-market ratios based on the ratio of individual firm's ratio to the long-run average book-to-market ratio for the the industry the firm is in. They construct an HML portfolio based on this measure and find that it has a considerably higher Sharperatio than the Fama and French (1993) HML portfolio (and is therefore more efficient). They redo the tests presented here with the more efficient portfolios and find that the factor model is still rejected in favor of the characteristic-based model.
} 
In addition, if the excess returns of distressed stocks do arise because of their sensitivity to an unobserved factor, it must be the case that the unobserved factor portfolios have significantly higher Sharpe ratios than not only the FF portfolios but also the more efficient portfolios of Cohen and Polk and Frankel and Lee. In other words, the payoff associated with bearing the risks associated with these distressed factors must be significantly greater than the payoff from holding the size and book-to-market factor portfolios. MacKinlay (1995) has suggested that the Sharpe ratio achievable using the three Fama and French (1993) factor portfolios is already "too large" to be explained by efficient market theories; would explain the returns of the portfolios in Table 5 would have still higher Sharpe ratios.

If expected returns are indeed based on characteristics rather risk, the implications for portfolio analysis, performance evaluation and corporate finance are striking. As we have already discussed, our results suggest that portfolios can be constructed which earn the book-to-market premium without loading heavily on common factors. This means that higher Sharpe ratios are achievable than was indicated by previous studies. In terms of performance evaluation,, our results suggest that comparing the evaluated returns to matched samples formed on the basis of capitalization, book-to-market and probably also past returns (to account for the Jegadeesh and Titman (1993) momentum effect) would be preferred to using the intercepts from regressions on factor portfolios. A recent example of the matched sample approach is Ikenberry, Lakonishok, and Vermaelen (1995). We are substantially more tentative about the implications of our results for corporate finance. It should be noted, however, that the characteristics model is inconsistent with the Modigliani and Miller (1958) theorem, so if we do want to take the characteristic-based pricing model seriously, we will have to rethink most of what we know about corporate finance.

However, before beginning to consider the implications of these results, it is worthwhile to consider why it might be that characteristics are the determinants of returns rather than risk. Lakonishok, Shleifer, and Vishny (1994) suggest a behavioral explanation: that investors may incorrectly extrapolate past growth rates. Lakonishok, Shleifer, and Vishny (1992) suggest an agency explanation: that investment fund managers are aware of the expected returns associated with value stocks, but nonetheless purchase growth stocks because these are easier to justify to sponsors. Liquidity-based explanations may also be plausible, since volume tends to be related to size and past returns, but the evidence in Table 9 suggests that the relationship between 
book-to-market and turnover is relatively weak.

Another possibility is that investors consistently held priors that size and book-to-market ratios were proxies for systematic risk and, as a result, attached higher discount rates to stocks with these characteristics. For example, they may have believed that stocks with these characteristics would be more sensitive to aggregate economic or credit conditions, beliefs that many financial economists shared. With the benefit of hindsight we can now say that book-to-market ratios do not seem to be particularly good proxies for systematic risk of this sort. However, we think it is quite plausible that investors in the 1960s and 1970s, with limited ability to access and manipulate the returns/accounting data that would have told them otherwise, would not have updated their priors as our statistical analysis suggests they should have. If this is the case than the patterns we have observed in the data should not be repeated in the future. 


\section{References}

Amihud, Yakov, and Haim Mendelson, 1986, Asset pricing and the bid-ask spread, Journal of Financial Economics 17, 223-249.

Banz, Rolf W., 1981, The relationship between return and the market value of common stocks, Journal of Financial and Quantitative Analysis 14, 421-441.

Basu, S., 1983, The relationship between earnings yield, market value, and return for NYSE common stocks, Journal of Financial Economics 12, 126-156.

Bhandari, Laxmi C., 1988, Debt/equity ratios and expected common stock returns: Empirical evidence, Journal of Finance 43, 507-528.

Chan, K. C., and Nai-Fu Chen, 1991, Structural and return characteristics of small and large firms, Journal of Finance 46, 1467-1484.

Chan, K. C., Nai-fu Chen, and David A. Hsieh, 1985, An exploratory investigation of the firm size effect, Journal of Financial Economics 14, 451-71.

Chan, Louis K.C., Narasimhan Jegadeesh, and Josef Lakonishok, 1995, Issues in evaluating the performance of value versus glamour stocks: Selection bias, risk adjustment and data snooping, Journal of Financial Economics 38, 269-296.

Chen, Nai-Fu, Richard Roll, and Stephen A. Ross, 1986, Economic forces and the stock market, Journal of Business 59, 383-403.

Cohen, Randolph B., and Christopher K. Polk, 1995a, COMPUSTAT selection bias in tests of the Sharpe-Litner-Black CAPM, University of Chicago working paper, October 1995.

- 1995b, An investigation of the impact of industry factors in asset-pricing tests, University of Chicago working paper, October 1995.

Connor, Gregory, and Robert A. Korajczyk, 1988, Risk and return in an equilibrium apt: Application of a new test methodology, Journal of Financial Economics 21, 255-289.

Davis, James L., 1994, The cross-section of realized stock returns: The pre-COMPUSTAT evidence, Journal of Finance 50, 1579-1593.

DeBondt, Werner F. M., and Richard Thaler, 1985, Does the stock market overreact?, Journal of Finance 40, 793-808.

Fama, Eugene F., and Kenneth R. French, 1992, The cross-section of expected stock returns, Journal of Finance 47, 427-465.

- 1993, Common risk factors in the returns on stocks and bonds, Journal of Financial Economics 33, 3-56. 
- 1994 , Industry costs of equity, University of Chicago working paper.

- 1995, Size and book-to-market factors in earnings and returns, Journal of Finance 50, 131-156.

- 1996, Multifactor explanations of asset pricing anomalies, Journal of Finance, forthcoming 51.

Frankel, Richard, and Charles Lee, 1995, Accounting valuation, market expectation, and the book-to-market effect, University of Michigan working paper.

Ikenberry, David, Josef Lakonishok, and Theo Vermaelen, 1995, Market underreaction to open market share repurchases, Journal of Financial Economics 39, 181-208.

Jagannathan, Ravi, and Zhenyu Wang, 1996, The CAPM is alive and well, Journal of Finance, forthcoming 51 .

Jegadeesh, Narasimhan, 1992, Does market risk really explain the size effect?, Journal of Financial and Quantitative Analysis 27, 337-351.

- and Sheridan Titman, 1993, Returns to buying winners and selling losers: Implications for stock market efficiency, Journal of Finance 48, 65-91.

Keim, Donald B., 1983, Size related anomalies and stock return seasonality: Further evidence, Journal of Financial Economics 12, 13-32.

Kothari, S.P., Jay Shanken, and Richard Sloan, 1995, Another look at the cross-section of expected returns, Journal of Finance 50, 185-224.

Lakonishok, Josef, Andrei Shleifer, and Robert W. Vishny, 1992, The structure and performance of the money management industry, Brookings Papers on Economic Activity: Microeconomics pp. 339-391.

- 1994, Contrarian investment, extrapolation and risk, Journal of Finance 49, 1541-1578.

Lehmann, Bruce, and David Modest, 1988, Empirical foundations of the arbitrage pricing theory, Journal of Financial Economics 21, 213-254.

MacKinlay, A. Craig, 1995, Multifactor models do not explain deviations from the CAPM, Journal of Financial Economics 38, 3-28.

Merton, Robert C., 1973, An intertemporal capital asset pricing model, Econometrica 41, 867887.

Modigliani, Franco, and Merton Miller, 1958, The cost of capital, corporation finance, and the theory of investment, American Economic Review 53, 261-297.

Roll, Richard W., 1994, Style return differentials: Illusions, risk premia, or investment opportunities?, UCLA AGSM Working Paper, August 1994.

Rosenberg, Barr, Kenneth Reid, and Ronald Lanstein, 1985, Persuasive evidence of market inefficiency, Journal of Portfolio Management 11, 9-17. 
Ross, Stephen A., 1976, The arbitrage theory of capital asset pricing, Journal of Economic Theory 13, 341-360.

Stattman, Dennis, 1980, Book values and stock returns, The Chicago MBA: A Journal of Selected Papers 4, 25-45. 


\section{A Appendix: Construction of the Portfolios}

The construction of the book-to-market and size portfolios follows Fama and French (1993). Using the merged CRSP/COMPUSTAT files maintained by CRSP we form portfolios of common shares based on the ratio of the book-equity to market equity (book-to-market) and on market equity (ME). B is defined to be stockholder's equity plus any deferred taxes and any investment tax credit, minus the value of any preferred stock, all from COMPUSTAT. To determine the value of preferred stock we use redemption value if this is available, otherwise we use liquidating value if it is available, and if not we use carrying value. In calculating book-to-market, we use the book-equity from any point in year $t$, and the market on the last trading day in year $t$, where the market equity, from CRSP, is defined as the number of shares outstanding times the share price. We only include firms in our analysis which have been listed on COMPUSTAT for at least two years and which have prices available on CRSP in both December of $t$ and June of year $t+1$. The book-to-market ratios, and sizes of the firms thus determined are then used to form the portfolios from July of $t+1$ to June of $t+2$. As discussed in Fama and French (1993), the end of June is used as the portfolio formation date because the annual report containing the book-equity value for the preceding year is virtually certain to be public information by that time.

To form the portfolio, we first exclude from the sample all firms with book-to-market values of less than zero. We take all NYSE stocks in the sample and rank them on their bookto-market and size as described above. Based on these rankings, we calculate $30 \%$ and $70 \%$ breakpoints for book-to-market and a $50 \%$ breakpoint for size. We then place all NYSE/AMEX and NASDAQ stocks into the three book-to-market groups and the two size groups based on these breakpoints. The stocks above the $70 \%$ book-to-market breakpoint are designated $H$, the middle $40 \%$ of firms are designated $M$, and the firms below the $30 \%$ book-to-market breakpoint are designated $L$. Also firms above the $50 \%$ size breakpoint are designated $B$ (for big), and the remaining $50 \% S$ (for small). Note that since these breakpoints are based only on NYSE firms, we have considerable variation in the number of firms in each of the nine portfolios formed in this way. For example, since there are many more small firms on NASDAQ and AMEX the number of firms in the small firm portfolios is much larger than the number of firms in the large firm portfolios.

These two sets of rankings allow us to form the six value-weighted portfolios $H B, M B, L B$, HS, MS, and LS. From these portfolio returns we calculate the SMB (Small-Minus- $B$ ig) portfolio returns, which are defined to be $r_{S M B}=\left(r_{H S}+r_{M S}+r_{L S}-r_{H B}-r_{M B}-r_{L B}\right) / 3$, and the $H M L$ (High-Minus-Low) portfolio returns, which are defined as $r_{H M L}=\left(r_{H B}+r_{H S}-r_{L B}-r_{L S}\right) / 2$. Also, a value-weighted portfolio $M k t$ is formed which contains all of the firms in these portfolios, plus the otherwise excluded firms with book-to-market values of less than zero. 
Figure 1: HML portfolio pre-formation returns

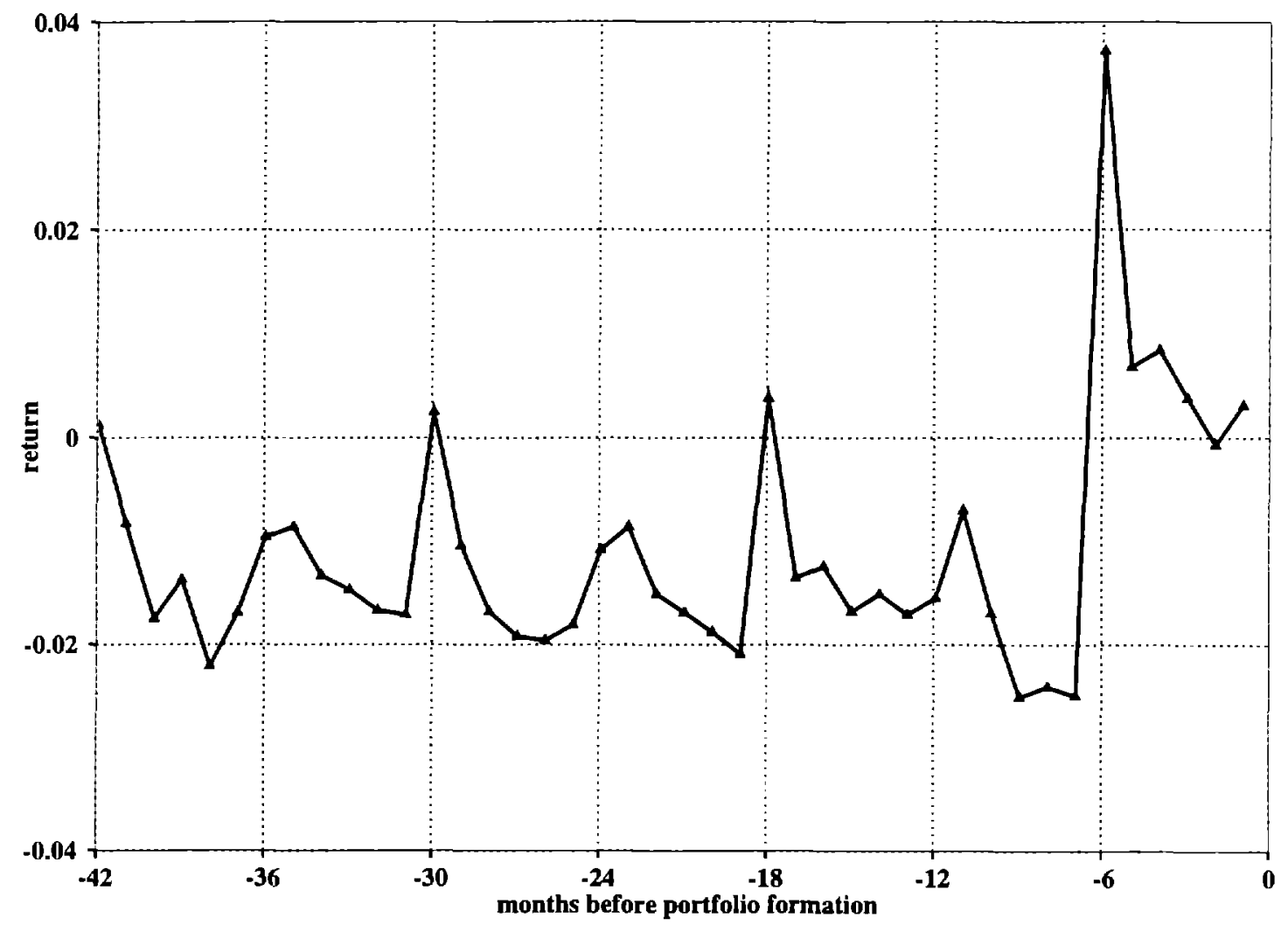


Table 1: Monthly mean excess returns (in percent) of size and book-to-market sorted portfolios (63:07-93:12).

We first rank all NYSE firms by their book-to-market at the end of year $t-1$ and their market capitalization (ME) at the end of June of year $t$, as described in the Appendix. We form quintile breakpoints for book-to-market and ME based on these rankings. Starting in July of year $t$, we then place all NYSE/AMEX and NASDAQ stocks into the five book-to-market groups and the five size groups based on these breakpoints. The firms remain in these portfolios from the beginning of July of year $t$ the end of June of year $t+1$.

Panel A presents the average of the monthly value weighted returns for each of these portfolios, net of the one month T-Bill return from the CRSP RISKFREE file. Panel B presents the average returns for January only, and Panel $C$ presents the average return, excluding the returns in January.

\begin{tabular}{|c|c|c|c|c|c|}
\hline \multicolumn{6}{|c|}{ Panel A: All Months } \\
\hline & low & bool & -to-m & rket & high \\
\hline \multirow[t]{2}{*}{ small } & 0.371 & 0.748 & 0.848 & 0.961 & 1.131 \\
\hline & 0.445 & 0.743 & 0.917 & 0.904 & 1.113 \\
\hline \multirow[t]{2}{*}{ size } & 0.468 & 0.743 & 0.734 & 0.867 & 1.051 \\
\hline & 0.502 & 0.416 & 0.627 & 0.804 & 1.080 \\
\hline big & 0.371 & 0.412 & 0.358 & 0.608 & 0.718 \\
\hline \multicolumn{6}{|c|}{ Panel B: Januarys only } \\
\hline & low & \multicolumn{3}{|c|}{ book-to-market } & high \\
\hline \multirow[t]{2}{*}{ small } & 6.344 & 6.091 & 6.254 & 6.827 & 8.087 \\
\hline & 3.141 & 4.456 & 4.522 & 4.914 & 6.474 \\
\hline \multirow[t]{2}{*}{ size } & 2.397 & 3.374 & 3.495 & 3.993 & 5.183 \\
\hline & 1.416 & 1.955 & 2.460 & 3.515 & 5.111 \\
\hline big & 0.481 & 1.224 & 1.205 & 2.663 & 4.043 \\
\hline \multicolumn{6}{|c|}{ Panel C: Non-Januarys only } \\
\hline & low & \multicolumn{3}{|c|}{ book-to-market } & high \\
\hline \multirow[t]{2}{*}{ small } & -0.162 & 0.271 & 0.365 & 0.438 & 0.510 \\
\hline & 0.204 & 0.412 & 0.595 & 0.545 & 0.635 \\
\hline \multirow[t]{2}{*}{ size } & 0.296 & 0.509 & 0.488 & 0.588 & 0.682 \\
\hline & 0.420 & 0.278 & 0.463 & 0.562 & 0.720 \\
\hline big & 0.361 & 0.340 & 0.283 & 0.424 & 0.421 \\
\hline
\end{tabular}


Table 2: Pre-formation monthly return standard deviations of portfolios This table presents pre-formation characteristics of the set of size and book-to-market portfolios. Six portfolios were formed based on unconditional sorts on book-to-market ( $H, M$, and $L$ ) and size (S and B). Mkt, SMB, HML portfolios were also formed as described in the Appendix. For this table, we also imposed the additional requirement that CRSP report a valid return for the firm five years (prior to/after) to the formation for the (forward/backward) looking analysis.

The formation year 0 returns consists of returns from July of year $t$ through June of year $t+1$ for valueweighted portfolios reformed each year at the end of June of year $t$, based on the BM at the end of year $t-1$ and the market value in June of $t$. These returns are approximately equivalent to those presented in Fama and French (1993). For formation years (FY) other than zero, the portfolio time series of returns consists again of the returns from July of year $t$ through June of year $t+1$, but now formed based on the BM at the end of year $t-1+F Y$ and the market value in June of $t+F Y$. The portfolio weights in these calculations are based on the market value in June of $t+F Y$.

Panel A presents the simple time-series standard deviations of each of these portfolios. For the backward looking portfolios, for each of the six lags, the return time series is from 63:07 to 89:06. For the forwardlooking portfolios, the time period is 68:07-93:12. Panel $\mathrm{B}$ also presents the time-series standard deviations the portfolios, but here the January returns are excluded from each of the time series.

\begin{tabular}{|c|c|c|c|c|c|c|c|c|c|c|c|c|}
\hline \multirow{3}{*}{$\begin{array}{c}\text { Size/ } \\
\text { BM } \\
\text { Portfol. }\end{array}$} & \multicolumn{12}{|c|}{ Formation Year } \\
\hline & \multicolumn{6}{|c|}{ Backward Looking } & \multicolumn{6}{|c|}{ Forward Looking } \\
\hline & 5 & 4 & 3 & 2 & 1 & 0 & 0 & -1 & -2 & -3 & -4 & -5 \\
\hline \multicolumn{13}{|c|}{ Panel A: Standard Deviations } \\
\hline $\mathrm{L} / \mathrm{S}$ & 7.01 & 6.94 & 6.95 & 6.97 & 6.74 & 6.61 & 6.56 & 6.60 & 6.70 & 6.62 & 6.57 & 6.41 \\
\hline $\mathrm{M} / \mathrm{S}$ & 5.73 & 5.77 & 5.74 & 5.67 & 5.61 & 5.55 & 5.25 & 5.36 & 5.46 & 5.45 & 5.43 & 5.42 \\
\hline $\mathrm{H} / \mathrm{S}$ & 5.74 & 5.73 & 5.69 & 5.70 & 5.97 & 5.67 & 5.25 & 5.18 & 5.38 & 5.48 & 5.47 & 5.40 \\
\hline L/B & 4.89 & 4.92 & 4.84 & 4.88 & 4.91 & 4.82 & 4.61 & 4.66 & 4.79 & 4.83 & 4.81 & 4.79 \\
\hline $\mathrm{M} / \mathrm{B}$ & 4.42 & 4.40 & 4.47 & 4.49 & 4.47 & 4.37 & 4.16 & 4.27 & 4.37 & 4.46 & 4.48 & 4.42 \\
\hline $\mathrm{H} / \mathrm{B}$ & 4.61 & 4.68 & 4.59 & 4.58 & 4.77 & 4.55 & 4.23 & 4.23 & 4.27 & 4.34 & 4.37 & 4.46 \\
\hline Mkt & 5.13 & 5.13 & 5.09 & 5.07 & 5.05 & 4.96 & 4.74 & 4.80 & 4.92 & 4.94 & 4.93 & 4.88 \\
\hline SMB & 3.04 & 3.02 & 2.96 & 2.88 & 2.78 & 2.80 & 2.63 & 2.68 & 2.76 & 2.79 & 2.78 & 2.75 \\
\hline HML & 2.20 & 2.29 & 2.53 & 2.88 & 3.30 & 2.55 & 2.51 & 2.28 & 2.12 & 2.13 & 2.20 & 2.21 \\
\hline \multicolumn{13}{|c|}{ Panel B: Standard Deviations - Januaries Excluded } \\
\hline $\mathrm{L} / \mathrm{S}$ & 6.63 & 6.54 & 6.60 & 6.66 & 6.59 & 6.31 & 6.22 & 6.15 & 6.20 & 6.17 & 6.06 & 5.90 \\
\hline $\mathrm{M} / \mathrm{S}$ & 5.32 & 5.37 & 5.33 & 5.28 & 5.27 & 5.16 & 4.84 & 4.92 & 5.03 & 5.00 & 5.01 & 5.01 \\
\hline $\mathrm{H} / \mathrm{S}$ & 5.30 & 5.26 & 5.13 & 5.09 & 5.21 & 5.11 & 4.63 & 4.67 & 4.91 & 5.03 & 5.07 & 4.99 \\
\hline $\mathrm{L} / \mathrm{B}$ & 4.83 & 4.85 & 4.76 & 4.77 & 4.82 & 4.73 & 4.46 & 4.48 & 4.58 & 4.62 & 4.62 & 4.61 \\
\hline $\mathrm{M} / \mathrm{B}$ & 4.33 & 4.30 & 4.34 & 4.37 & 4.27 & 4.21 & 3.90 & 4.08 & 4.17 & 4.27 & 4.25 & 4.21 \\
\hline $\mathrm{H} / \mathrm{B}$ & 4.42 & 4.45 & 4.33 & 4.27 & 4.32 & 4.27 & 3.88 & 3.87 & 4.05 & 4.14 & 4.23 & 4.27 \\
\hline Mkt & 4.89 & 4.87 & 4.82 & 4.79 & 4.76 & 4.68 & 4.40 & 4.45 & 4.59 & 4.62 & 4.62 & 4.57 \\
\hline SMB & 2.74 & 2.71 & 2.66 & 2.60 & 2.62 & 2.56 & 2.39 & 2.41 & 2.47 & 2.54 & 2.54 & 2.52 \\
\hline HML & 2.20 & 2.31 & 2.46 & 2.76 & 2.92 & 2.45 & 2.38 & 2.24 & 2.09 & 2.09 & 2.15 & 2.18 \\
\hline
\end{tabular}


Table 3: Mean excess returns of the $\mathbf{4 5}$ portfolios formed on the basis of size, book-to-market and HML factor loadings

We first rank all NYSE firms by their book-to-market at the end of year $t-1$ and their market capitalization (ME) at the end of June of year $t$, as described in the Appendix. We form $33.3 \%$ and $66.7 \%$ breakpoints for book-to-market and ME based on these rankings. Starting in July of year $t$, we then place all NYSE/AMEX and NASDAQ stocks into the three book-to-market groups and the three size groups based on these breakpoints. The firms remain in these portfolios from the beginning of July of year $t$ the end of June of year $t+1$. Each of the individual firms in these nine portfolios is then further sorted into one of five sub-portfolios based on their $\beta_{H M L}$ coefficients in the regression:

$$
\tilde{R}_{i, j, k}-R_{f}=\alpha+\beta_{H M L} \cdot \tilde{R}_{H M L}+\beta_{S M B} \cdot \tilde{R}_{S M B}+\beta_{M k t} \cdot\left(\tilde{R}_{M k t}-R_{f}\right)
$$

The regression is run between 42 months and 6 months prior to the formation date (June of year $t$ ), as is described in Section 5.1. The value-weighted returns for each of these portfolios are then calculated for each month between July 1973 and December 1993. The formation process results in portfolios which are buy-and-hold, and which are rebalanced at the end of June of each year

This table presents the mean excess returns of the $\mathbf{4 5}$ portfolios formed on the basis of size (Sz), bookto-market (book-to-market) and the estimated factor loadings on the HML portfolio, for the period from July 1973 through December of 1993. Each of the five columns provides the monthly excess returns of portfolios of stocks that are ranked in a particular quintile with respect to the HML factor loading (with column 1 being the lowest and column 5 being the highest). The firm size and book-to-market rankings of the stocks in each of the portfolios are specified in the 9 rows. For example, the top left entry in the table (0.202) is the mean excess return of a value-weighted portfolio of the stocks that have the smallest size, the lowest book-to-market and the lowest expected loading on the HML factor.

\begin{tabular}{|c|c||ccccc|}
\hline \multicolumn{3}{|c||}{ Char Port } & \multicolumn{5}{c|}{ factor loading portfolio } \\
\hline $\mathrm{BM}$ & $\mathrm{Sz}$ & 1 & 2 & 3 & 4 & 5 \\
\hline \hline 1 & 1 & 0.202 & 0.833 & 0.902 & 0.731 & 0.504 \\
1 & 2 & 0.711 & 0.607 & 0.776 & 0.872 & 0.710 \\
1 & 3 & 0.148 & 0.287 & 0.396 & 0.400 & 0.830 \\
\hline 2 & 1 & 1.036 & 0.964 & 1.014 & 1.162 & 0.862 \\
2 & 2 & 0.847 & 0.957 & 0.997 & 0.873 & 0.724 \\
2 & 3 & 0.645 & 0.497 & 0.615 & 0.572 & 0.718 \\
\hline 3 & 1 & 1.211 & 1.112 & 1.174 & 1.265 & 0.994 \\
3 & 2 & 1.122 & 1.166 & 1.168 & 1.080 & 0.955 \\
3 & 3 & 0.736 & 0.933 & 0.571 & 0.843 & 0.961 \\
\hline \hline \multicolumn{2}{|c|}{ average } & 0.740 & 0.817 & 0.846 & 0.866 & 0.806 \\
\hline
\end{tabular}


Table 4: Average Book-to-Market and Size of Test Portfolios

Portfolios were formed based on size, book-to-market and pre-formation HML factor loadings as described in Table 3. At each yearly formation date, the average size and book-to-market for each portfolio was then calculated, using value weighting:

$$
\overline{S Z}_{t}=\frac{1}{\sum_{i} M E_{i, t}} \sum_{i} M E_{i, t}^{2} \quad \overline{B M}_{t}=\frac{1}{\sum_{i} M E_{i, t}} \sum_{i} B M_{i, t} \cdot M E_{i, t}
$$

Then, at each point, $\overline{S Z}_{t}$ and $\overline{B M}_{t}$ were divided by the median ME and median book-to-market for NYSE firms at that point in time. The two time series were then averaged to get the numbers that are presented in the table below.

\begin{tabular}{|c|c|c|c|c|c|c|}
\hline \multicolumn{2}{|c|}{ Chr Prt } & \multicolumn{5}{|c|}{ factor loading portfolio } \\
\hline$B M$ & $S z$ & 1 & 2 & 3 & 4 & 5 \\
\hline & & \multicolumn{5}{|c|}{ Book-to-Market relative to median } \\
\hline 1 & 1 & 0.415 & 0.466 & 0.492 & 0.501 & 0.440 \\
\hline 1 & 2 & 0.404 & 0.453 & 0.487 & 0.501 & 0.505 \\
\hline 1 & 3 & 0.360 & 0.399 & 0.457 & 0.507 & 0.542 \\
\hline 2 & 1 & 0.980 & 0.991 & 1.013 & 1.017 & 1.011 \\
\hline 2 & 2 & 0.963 & 0.996 & 1.003 & 1.013 & 1.021 \\
\hline 2 & 3 & 0.949 & 0.975 & 0.998 & 1.027 & 1.025 \\
\hline$\overline{3}$ & $\mathbf{1}$ & 1.908 & 1.841 & 1.876 & 1.941 & 2.242 \\
\hline 3 & 2 & 1.624 & 1.725 & 1.708 & 1.732 & 1.890 \\
\hline 3 & 3 & 1.568 & 1.563 & 1.554 & 1.638 & 1.747 \\
\hline \multicolumn{2}{|c|}{ average } & 1.019 & 1.045 & 1.065 & 1.097 & 1.158 \\
\hline & & \multicolumn{5}{|c|}{ Market Equity relative to median } \\
\hline 1 & 1 & 0.239 & 0.262 & 0.255 & 0.251 & 0.212 \\
\hline 1 & 2 & 1.178 & 1.235 & 1.280 & 1.239 & 1.240 \\
\hline 1 & 3 & 34.716 & 42.269 & 55.325 & 30.111 & 24.842 \\
\hline 2 & $\mathbf{1}$ & 0.226 & 0.248 & 0.265 & 0.264 & 0.239 \\
\hline 2 & 2 & 1.194 & 1.171 & 1.197 & 1.205 & 1.204 \\
\hline 2 & 3 & 23.951 & 41.405 & 27.428 & 25.675 & 21.163 \\
\hline$\overline{3}$ & 1 & 0.173 & 0.207 & 0.227 & 0.237 & 0.205 \\
\hline 3 & 2 & 1.146 & 1.187 & 1.215 & 1.217 & 1.191 \\
\hline 3 & 3 & 10.615 & 27.661 & 21.152 & 11.626 & 15.288 \\
\hline \multicolumn{2}{|c|}{ average } & 8.160 & 12.849 & 12.038 & 7.981 & 7.287 \\
\hline
\end{tabular}


Table 5: Portfolios Sorted by Characteristics and Predicted HML Factor Loadings

Portfolios were formed based on size, book-to-market and pre-formation HML factor loadings as described in Table 3. This table presents each of the coefficients estimates and T-Statistics from the following timeseries regression of these portfolio returns on the excess-Market, SMB and HML portfolio returns:

$$
\bar{R}_{s z, b m, f l}-R_{f}=\alpha+\beta_{H M L} \cdot \tilde{R}_{H M L}+\beta_{S M B} \cdot \tilde{R}_{S M B}+\beta_{M k t} \cdot\left(\tilde{R}_{M k t}-R_{f}\right)
$$

\begin{tabular}{|c|c|c|c|c|c|c|c|c|c|c|c|}
\hline \multicolumn{2}{|c|}{ Chr Prt } & \multicolumn{5}{|c|}{ factor loading portfolio } & \multicolumn{5}{|c|}{ factor loading portfolio } \\
\hline$\overline{\mathrm{BM}}$ & $\mathrm{Sz}$ & 1 & 2 & 3 & 4 & 5 & 1 & 2 & 3 & 4 & 5 \\
\hline & & \multicolumn{5}{|c|}{$\hat{\alpha}$} & \multicolumn{5}{|c|}{$T(\hat{\alpha})$} \\
\hline 1 & 1 & -0.58 & 0.14 & 0.06 & -0.17 & -0.67 & -3.97 & 1.04 & 0.48 & -1.34 & -4.00 \\
\hline 1 & 2 & 0.16 & 0.05 & 0.13 & 0.16 & -0.08 & 0.94 & 0.47 & 1.12 & 1.33 & -0.63 \\
\hline 1 & 3 & 0.02 & 0.05 & 0.06 & -0.06 & 0.28 & 0.15 & 0.42 & 0.50 & -0.55 & 2.26 \\
\hline 2 & 1 & $\overline{0.13}$ & 0.08 & 0.06 & 0.21 & -0.31 & 1.05 & 0.87 & 0.73 & 2.13 & -2.31 \\
\hline 2 & 2 & 0.03 & 0.20 & 0.22 & 0.01 & -0.31 & 0.24 & 1.71 & 2.05 & 0.14 & -2.66 \\
\hline 2 & 3 & 0.19 & -0.08 & 0.05 & -0.10 & -0.07 & 1.13 & -0.50 & 0.35 & -0.67 & -0.46 \\
\hline 3 & 1 & 0.08 & 0.05 & 0.10 & 0.01 & -0.47 & 0.70 & 0.55 & 1.06 & 0.10 & -3.27 \\
\hline 3 & 2 & 0.17 & 0.22 & 0.25 & 0.05 & -0.31 & 1.25 & 1.67 & 1.94 & 0.36 & -1.63 \\
\hline 3 & 3 & -0.01 & 0.16 & -0.23 & -0.12 & -0.18 & -0.04 & 1.13 & -1.45 & -0.74 & -0.90 \\
\hline \multicolumn{2}{|c|}{ average } & 0.02 & 0.10 & 0.08 & 0.00 & -0.24 & 0.16 & 0.82 & 0.75 & 0.08 & -1.51 \\
\hline & & \multicolumn{5}{|c|}{$\hat{\beta}_{H M L}$} & \multicolumn{5}{|c|}{$T\left(\hat{\beta}_{H M L}\right)$} \\
\hline 1 & 1 & -0.40 & -0.38 & -0.11 & -0.04 & 0.25 & -7.09 & -7.09 & -2.32 & -0.84 & 3.91 \\
\hline 1 & 2 & -0.60 & -0.32 & -0.18 & -0.05 & 0.05 & -9.13 & -7.15 & -3.98 & -1.02 & 1.01 \\
\hline 1 & 3 & -0.70 & -0.44 & -0.22 & -0.11 & -0.02 & -12.85 & -9.85 & -4.72 & -2.48 & -0.44 \\
\hline 2 & 1 & 0.02 & 0.19 & 0.32 & 0.35 & 0.48 & 0.39 & 5.51 & 9.69 & 9.06 & 9.13 \\
\hline 2 & 2 & 0.17 & 0.23 & 0.28 & 0.36 & 0.49 & 3.23 & 5.14 & 6.59 & 8.67 & 10.98 \\
\hline 2 & 3 & 0.03 & 0.24 & 0.22 & 0.31 & 0.49 & 0.50 & 3.90 & 4.03 & 5.53 & 8.40 \\
\hline 3 & 1 & $\overline{0.42}$ & 0.50 & 0.57 & 0.75 & 0.91 & 9.74 & 13.00 & 16.26 & 19.74 & 16.11 \\
\hline 3 & 2 & 0.40 & 0.58 & 0.56 & 0.72 & 0.82 & 7.32 & 11.40 & 11.07 & 13.91 & 11.26 \\
\hline 3 & 3 & 0.45 & 0.56 & 0.67 & 0.81 & 1.00 & 6.69 & 10.03 & 10.91 & 12.81 & 12.90 \\
\hline \multicolumn{2}{|c|}{ average } & -0.02 & 0.13 & 0.23 & 0.34 & 0.50 & -0.13 & 2.77 & 5.28 & 7.26 & 8.14 \\
\hline & & \multicolumn{5}{|c|}{$\overline{\hat{\beta}_{S M B}}$} & \multicolumn{5}{|c|}{$T\left(\hat{\beta}_{S M B}\right)$} \\
\hline 1 & 1 & 1.23 & 1.07 & 1.07 & 1.18 & 1.39 & 23.27 & 21.29 & 24.34 & 26.33 & 22.97 \\
\hline 1 & 2 & 0.81 & 0.55 & 0.62 & 0.55 & 0.61 & 13.06 & 13.04 & 14.93 & 12.78 & 14.18 \\
\hline 1 & 3 & -0.14 & -0.17 & -0.16 & -0.08 & 0.04 & -2.84 & -4.16 & -3.59 & -1.88 & 0.83 \\
\hline 2 & 1 & 1.19 & 0.95 & 0.94 & 0.89 & 1.15 & 27.05 & 29.40 & 30.56 & 24.74 & 23.63 \\
\hline 2 & 2 & 0.54 & 0.45 & 0.44 & 0.47 & 0.72 & 10.99 & 10.87 & 11.09 & 12.10 & 17.12 \\
\hline 2 & 3 & -0.22 & -0.25 & -0.15 & -0.10 & -0.07 & -3.63 & -4.39 & -3.02 & -1.96 & -1.21 \\
\hline 3 & 1 & 1.24 & 1.01 & 0.95 & 1.04 & 1.25 & 30.74 & 27.73 & 28.97 & 29.27 & 23.67 \\
\hline 3 & 2 & 0.61 & 0.43 & 0.37 & 0.43 & 0.69 & 12.08 & 9.09 & 7.86 & 8.80 & 10.17 \\
\hline 3 & 3 & -0.06 & -0.15 & -0.17 & 0.05 & 0.10 & -1.02 & -2.90 & -3.04 & 0.82 & 1.35 \\
\hline \multicolumn{2}{|c|}{ average } & 0.58 & 0.43 & 0.43 & 0.49 & 0.65 & 12.19 & 11.11 & 12.01 & 12.33 & 12.52 \\
\hline & & \multicolumn{5}{|c|}{$\hat{\beta}_{M k t}$} & \multicolumn{5}{|c|}{$T\left(\hat{\beta}_{M k t}\right)$} \\
\hline 1 & 1 & 1.12 & 1.03 & 1.07 & 1.04 & 1.15 & 33.32 & 32.30 & $\overline{38.04}$ & 36.38 & 29.66 \\
\hline 1 & 2 & 1.14 & 1.03 & 1.03 & 1.07 & 1.08 & 28.90 & 38.38 & 38.90 & 39.26 & 39.07 \\
\hline 1 & 3 & 0.99 & 0.98 & 0.95 & 1.04 & 1.04 & 30.72 & 36.77 & 33.61 & 38.47 & 36.39 \\
\hline 2 & 1 & 0.99 & 0.93 & 0.95 & 0.95 & 1.08 & 35.45 & 45.11 & 48.49 & 41.54 & 34.84 \\
\hline 2 & 2 & 1.06 & 0.96 & 0.94 & 1.01 & 1.06 & 33.42 & 35.91 & 37.40 & 41.19 & 39.56 \\
\hline 2 & 3 & 0.97 & 1.02 & 0.96 & 1.04 & 1.07 & 25.56 & 28.22 & 29.97 & 31.22 & 30.42 \\
\hline 3 & 1 & 1.01 & 0.92 & 0.94 & 1.05 & 1.17 & 39.10 & 39.96 & 45.23 & 46.16 & 34.94 \\
\hline 3 & 2 & 1.05 & 0.99 & 0.98 & 1.02 & 1.20 & 32.59 & 32.78 & 32.32 & 32.82 & 27.74 \\
\hline 3 & 3 & 1.02 & 1.03 & 0.99 & 1.03 & 1.15 & 25.81 & 31.25 & 26.97 & 27.20 & 24.96 \\
\hline \multicolumn{2}{|l|}{ avera } & 1.04 & 0.99 & 0.98 & 1.03 & 1.11 & 31.65 & 35.63 & 36.77 & 37.14 & 33.06 \\
\hline
\end{tabular}




\section{Table 6: Regression Results for the Characteristic-Balanced Portfolios}

This table presents each of the coefficients and T-Statistics from the following time-series regression of the zero-investment portfolio returns, described below, on the excess-Market, SMB and HML portfolio returns:

$$
R_{i, j, k}-R_{f}=\alpha+\beta_{M k t} \cdot R_{M k t}+\beta_{H M L} \cdot R_{H M L}+\beta_{S M B} \cdot R_{S M B}
$$

The regressions are over the period July 1973 to December 1993.

The left hand side portfolios were formed based on size, book-to-market and pre-formation HML factor loadings, and their returns were calculated in the manner described in Table 3. From the resulting forty-five returns series, a zero-investment returns series was generated from each of the nine size and book-to-market categories. These portfolios are formed, in each category, by subtracting the sum of the returns on the 4th and 5th quintile factor-loading portfolios from the sum of the returns on 1st and 2nd factor-loading portfolios.

The first 9 rows of the table present the t-statistics for the characteristic-balanced portfolio that has a long position in the low expected factor loading portfolios and a short position in the high expected factor loading portfolios that have the same size and book-to-market rankings. The bottom row of the table provides the coefficient estimates as well as the t-statistics for this regression for a single portfolio that consists of an equally-weighted combination of the above 9 zero-investment portfolios.

\begin{tabular}{|c|c|c|c|c|c|c|}
\hline \multicolumn{2}{|c|}{ Chr Prt } & \multicolumn{5}{|c|}{ Char-Balanced Portfolio: $T$-Statistics } \\
\hline$\overline{\mathrm{BM}}$ & $\overline{\mathrm{Sz}}$ & $\hat{\alpha}$ & $\hat{\beta}_{M k t}$ & $\hat{\beta}_{S M B}$ & $\hat{\beta}_{H M L}$ & $R^{2}$ \\
\hline 1 & 1 & 1.43 & -0.43 & -2.69 & -9.21 & 31.48 \\
\hline 1 & 2 & 0.50 & 0.18 & 1.98 & -8.99 & 31.48 \\
\hline 1 & 3 & -0.48 & -1.62 & -2.52 & -8.57 & 27.11 \\
\hline 2 & & 1.37 & -2.02 & 1.31 & -7.13 & 18.43 \\
\hline 2 & 2 & 2.12 & -0.99 & -2.07 & -4.69 & 10.96 \\
\hline 2 & 3 & 0.79 & -1.41 & -2.34 & -3.96 & 9.11 \\
\hline 3 & 1 & 2.53 & -5.30 & -0.48 & -8.00 & 23.36 \\
\hline 3 & 2 & 2.01 & -2.30 & -0.63 & -4.52 & 8.58 \\
\hline 3 & 3 & 1.08 & -1.30 & -2.36 & -4.98 & 12.39 \\
\hline \multicolumn{2}{|c|}{$\begin{array}{c}\text { single } \\
\text { portfolio }\end{array}$} & $\begin{array}{l}0.354 \\
(2.30)\end{array}$ & $\begin{array}{l}-0.110 \\
(-3.10)\end{array}$ & $\begin{array}{l}-0.134 \\
(-2.40)\end{array}$ & $\begin{array}{c}-0.724 \\
(-12.31)\end{array}$ & 41.61 \\
\hline
\end{tabular}


Table 7: Time-series Regressions - SMB Factor loading-sorted portfolios

The upper two panels present the intercepts and $r_{S M B}$ coefficient estimates and T-Statistics from the following multivariate time-series regression:

$$
\tilde{R}_{s z, b m, f l}-R_{f}=\alpha+\beta_{H M L} \cdot \bar{R}_{H M L}+\beta_{S M B} \cdot \bar{R}_{S M B}+\beta_{M k t} \cdot\left(\bar{R}_{M k t}-R_{f}\right)
$$

The coefficient estimates for $\beta_{H M L}$ and $\beta_{M k t}$ are not presented here.

The left hand side portfolios were formed based on size, book-to-market and pre-formation SMB factor loadings as described in Table 3, with the exception that the factor loadings used to form the portfolios were the SMB factor loadings (rather than the HML factor loadings).

The lower panel gives the mean returns for each of the portfolios and the T-statistics for the regressions of the characteristic-balanced portfolios on the three factors, as described in Table 6.

\begin{tabular}{|c|c|c|c|c|c|c|c|c|c|c|c|c|}
\hline \multicolumn{2}{|c|}{ Chr Prt } & \multicolumn{6}{|c|}{$\hat{\alpha}$} & \multicolumn{5}{|c|}{$T(\hat{\alpha})$} \\
\hline$\overline{\mathrm{BM}}$ & $\mathrm{Sz}$ & 1 & 2 & & & 4 & 5 & 1 & 2 & 3 & 4 & 5 \\
\hline 1 & 1 & -0.28 & -0.01 & & 06 & -0.10 & -0.65 & -1.94 & -0.06 & -0.44 & -0.75 & -3.58 \\
\hline 1 & 2 & 0.07 & 0.20 & & & 0.01 & 0.01 & 0.57 & 1.79 & 1.10 & 0.08 & 0.03 \\
\hline 1 & 3 & 0.25 & 0.06 & & & -0.08 & 0.05 & 2.40 & 0.55 & 0.06 & -0.67 & 0.38 \\
\hline 2 & 1 & 0.16 & 0.07 & & & -0.05 & 0.06 & 1.38 & 0.73 & 0.69 & -0.48 & 0.37 \\
\hline 2 & 2 & 0.11 & -0.10 & & & 0.12 & -0.05 & 0.84 & -0.87 & 0.54 & 1.05 & -0.38 \\
\hline 2 & 3 & 0.08 & 0.01 & & & 0.10 & -0.03 & 0.50 & 0.08 & -1.04 & 0.88 & -0.27 \\
\hline 3 & 1 & $\overline{0.02}$ & 0.11 & & & -0.13 & -0.11 & $\overline{0.21}$ & 1.14 & -0.63 & -1.14 & -0.75 \\
\hline 3 & 2 & 0.19 & 0.23 & & & -0.01 & 0.15 & 1.20 & 1.79 & -0.91 & -0.07 & 0.75 \\
\hline 3 & 3 & 0.23 & -0.10 & & & -0.38 & 0.08 & 1.29 & -0.67 & -1.09 & -2.58 & 0.45 \\
\hline \multicolumn{2}{|c|}{ average } & 1.04 & 0.99 & & & 1.03 & 1.11 & 31.6 & 35.63 & 36.77 & 37.14 & 33.06 \\
\hline \multicolumn{2}{|c|}{ Chr Prt } & \multicolumn{6}{|c|}{$\hat{\beta}_{S M B}$} & \multicolumn{5}{|c|}{$T\left(\hat{\beta}_{S M B}\right)$} \\
\hline$\overline{\mathrm{BM}}$ & $\mathrm{Sz}$ & 1 & 2 & \multicolumn{2}{|c|}{3} & 4 & 5 & 1 & 2 & 3 & 4 & 5 \\
\hline 1 & 1 & 1.01 & 1.06 & \multicolumn{2}{|c|}{1.18} & 1.20 & 1.45 & 19.14 & $\overline{24.93}$ & 26.04 & 25.18 & 21.96 \\
\hline 1 & 2 & 0.49 & 0.54 & \multicolumn{2}{|c|}{0.59} & 0.71 & 0.84 & 11.33 & 13.21 & 13.38 & \multirow{2}{*}{$\begin{array}{c}15.00 \\
-0.69\end{array}$} & 15.40 \\
\hline 1 & 3 & -0.29 & -0.11 & \multicolumn{2}{|c|}{-0.11} & -0.03 & 0.15 & -7.81 & -2.58 & -2.50 & & 2.89 \\
\hline$\overline{2}$ & 1 & 0.84 & 0.85 & & & 1.17 & 1.57 & 20.5 & 26.15 & 26.53 & 29.86 & 28.18 \\
\hline 2 & 2 & 0.25 & 0.45 & & & 0.67 & 0.86 & 5.29 & 10.74 & 12.01 & 16.38 & 18.15 \\
\hline 2 & 3 & -0.38 & -0.26 & & & 0.06 & 0.25 & -6.3 & -5.46 & -2.54 & 1.44 & 5.44 \\
\hline 3 & 1 & 0.89 & 0.93 & & & 1.23 & 1.49 & 21.3 & 26.51 & 30.70 & 28.70 & 27.07 \\
\hline 3 & 2 & 0.12 & 0.34 & & & 0.65 & 0.91 & 2.05 & 7.43 & 11.53 & 12.56 & 12.96 \\
\hline 3 & 3 & -0.33 & -0.11 & & & 0.00 & 0.20 & -5.2 & -2.04 & 0.87 & 0.01 & 3.21 \\
\hline ave & & 0.29 & 0.41 & & & 0.63 & 0.86 & 6.70 & 10.99 & 12.89 & 14.27 & 15.03 \\
\hline Chr & & & Mea & n ret & rns: & & & har-F & Balanced & Portfolic & $T$-Stat & stics \\
\hline $\mathrm{BM}$ & $\mathrm{Sz}$ & 1 & 2 & 3 & 4 & 5 & & & $\hat{\beta}_{M k t}$ & $\hat{\beta}_{S M B}$ & $\hat{\beta}_{H M L}$ & $R^{2}$ \\
\hline 1 & 1 & 0.52 & 0.80 & 0.79 & 0.75 & 0.38 & & & -3.85 & -6.15 & 0.75 & 25.84 \\
\hline 1 & 2 & 0.64 & 0.84 & 0.81 & 0.65 & 0.75 & & & -3.37 & -5.47 & 2.10 & 24.16 \\
\hline 1 & 3 & 0.49 & 0.38 & 0.30 & 0.35 & 0.46 & & & -3.82 & -5.12 & 0.13 & 20.98 \\
\hline 2 & 1 & 1.09 & 0.93 & 1.03 & 0.94 & 1.22 & & & -5.51 & -11.72 & 2.82 & 52.98 \\
\hline 2 & 2 & 0.85 & 0.69 & 0.87 & 1.00 & 1.01 & -0 . & & -5.74 & -8.56 & 0.53 & 40.82 \\
\hline 2 & 3 & 0.57 & 0.54 & 0.42 & 0.80 & 0.86 & 0. & & -4.23 & -8.19 & -1.56 & 33.03 \\
\hline 3 & $\overline{1}$ & 1.13 & 1.23 & 1.14 & 1.15 & 1.27 & & & -6.15 & -9.29 & 0.78 & 44.85 \\
\hline 3 & 2 & & 1.23 & 0.96 & 1.09 & 1.29 & 0 . & & -4.81 & -8.25 & 2.11 & 39.09 \\
\hline 3 & 3 & 0.84 & 0.72 & 0.77 & 0.69 & 1.08 & 1. & & -6.02 & -4.80 & -2.13 & 26.41 \\
\hline $\begin{array}{l}\text { aver } \\
\text { (T-s }\end{array}$ & & 0.79 & 0.82 & 0.79 & 0.82 & 0.92 & 0.2 & & $\begin{array}{l}-0.331 \\
(-9.25)\end{array}$ & $\begin{array}{c}-0.790 \\
(-14.10)\end{array}$ & $\begin{array}{c}0.057 \\
(0.96)\end{array}$ & \\
\hline
\end{tabular}




\section{Table 8: Time-series regressions - Mkt Factor loading-sorted portfolios}

The upper two panels present the intercepts, $r_{M k t}$ coefficient estimates and T-Statistics from the following multivariate time-series regression:

$$
\bar{R}_{s z, b m, f l}-R_{f}=\alpha+\beta_{H M L} \cdot \bar{R}_{H M L}+\beta_{S M B} \cdot \bar{R}_{S M B}+\beta_{M k t} \cdot\left(\tilde{R}_{M k t}-R_{f}\right)
$$

The coefficient estimates for $\beta_{H M L}$ and $\beta_{S M B}$ are not presented here.

The left-hand-side portfolios were formed based on size, book-to-market and pre-formation MKT factor loadings as described in Table 3, with the exception that the factor loading used to sort the portfolios was the MKT factor loading (rather than the HML factor loading).

The lower panel gives the mean returns for each of the portfolios and the T-statistics for the regressions of the characteristic-balanced portfolios on the three factors, as described in Table 6.

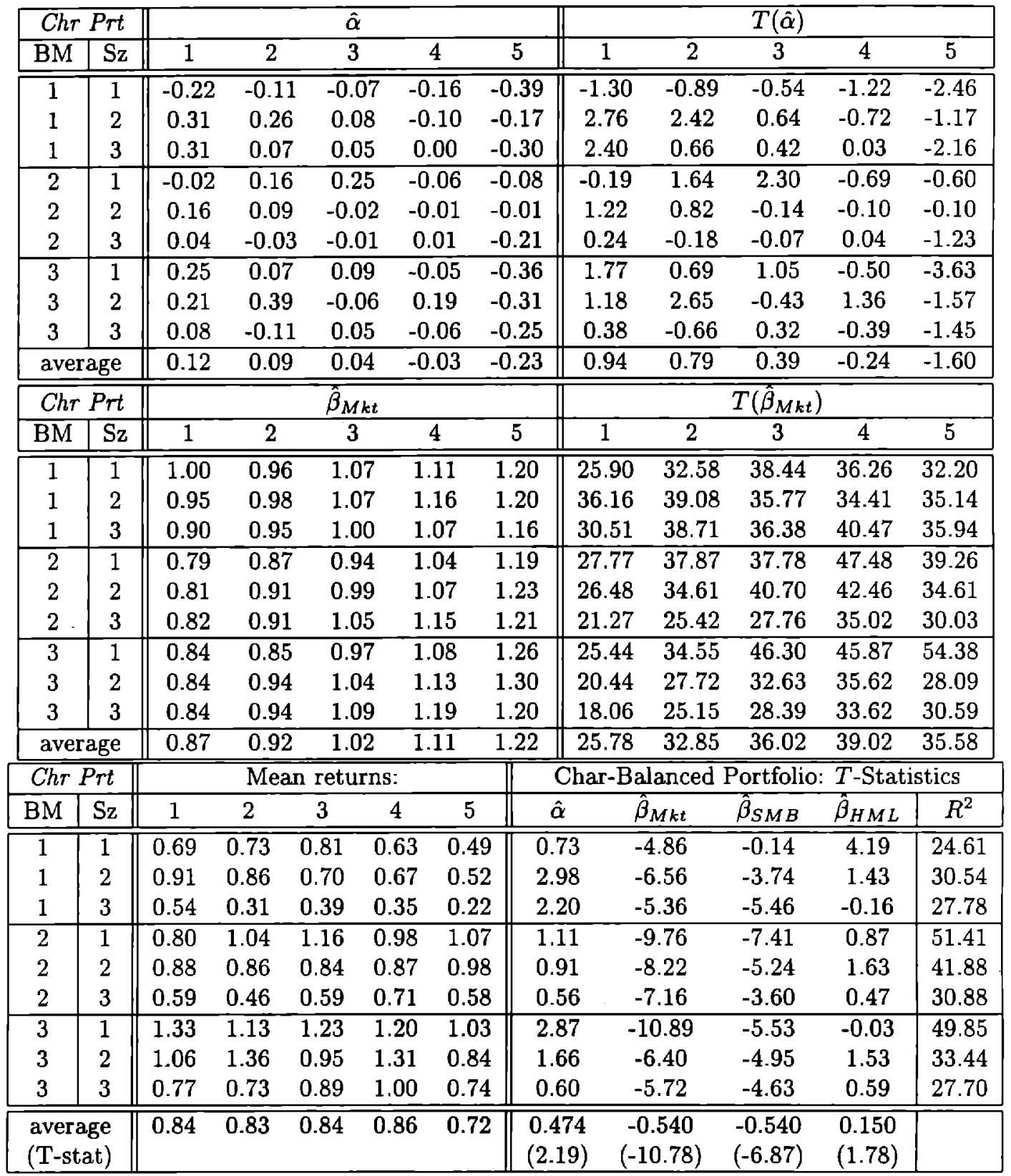


Table 9: Average Turnover for Portfolios sorted by Size, BM, and HML Loading

Portfolios were formed based on size, book-to-market and pre-formation HML factor loadings as described in Table 3. The numbers presented are the average turnover for each of the portfolios, for the period 1973:07-1993:12, where turnover is defined as the trading volume for the month (as reported by CRSP) divided by the number of shares outstanding at the beginning of the month, times 1000 . The averages are value-weighted, so turnover in month $t$ is defined as

$$
\text { Turnover }_{t}=\frac{1}{\sum_{i} M E_{i, t}} \sum_{i}\left(\frac{\mathrm{VOL}_{i, t}}{\mathrm{NS}_{i, t}}\right) \cdot M E_{i, t}
$$

\begin{tabular}{|c|c||r|r|r|r|r|}
\hline \multicolumn{3}{|c||}{$C h r$ Prt } & \multicolumn{5}{c|}{ factor loading portfolio } \\
\hline $\mathrm{BM}$ & $\mathrm{Sz}$ & 1 & 2 & 3 & 4 & 5 \\
\hline \hline 1 & 1 & 75.6 & 66.1 & 60.3 & 60.1 & 58.7 \\
1 & 2 & 96.6 & 61.8 & 50.6 & 47.4 & 56.3 \\
1 & 3 & 52.7 & 39.3 & 37.9 & 41.1 & 45.8 \\
\hline 2 & 1 & 61.9 & 43.7 & 40.2 & 40.2 & 46.2 \\
2 & 2 & 62.3 & 42.5 & 38.4 & 39.9 & 42.8 \\
2 & 3 & 44.6 & 39.3 & 37.6 & 38.7 & 39.9 \\
\hline 3 & 1 & 49.1 & 38.6 & 38.2 & 42.0 & 45.4 \\
3 & 2 & 56.2 & 43.1 & 44.7 & 44.2 & 51.6 \\
3 & 3 & 49.0 & 41.5 & 38.8 & 45.9 & 44.5 \\
\hline \multicolumn{2}{|c||}{ average } & 60.89 & 46.21 & 42.97 & 44.39 & 47.91 \\
\hline
\end{tabular}

\section{Table 10: Mean Past 12-Month Return of Test Portfolios}

Portfolios were formed based on size, book-to-market and pre-formation HML factor loadings as described in Table 3. At each yearly formation date, the average past 12-month return for each portfolio was calculated using value weighting:

$$
\bar{\tau}_{t-\tau 1, t-\tau 2}=\frac{1}{\sum_{i} M E_{i, t}} \sum_{i} M E_{i, t} \cdot \tau_{i, t-11, t}
$$

\begin{tabular}{|c|c|c|c|c|c|c|c|}
\hline \multicolumn{2}{|c|}{ Chr Prt } & \multicolumn{5}{|c|}{ factor loading portfolio } & \multirow[b]{2}{*}{$5-1$} \\
\hline$\overline{B M}$ & $\mathrm{Sz}$ & 1 & 2 & 3 & 4 & 5 & \\
\hline 1 & 1 & 1.74 & 1.83 & 1.79 & 1.77 & 1.50 & -0.24 \\
\hline 1 & 2 & 2.59 & 2.15 & 1.79 & 1.88 & 1.93 & -0.66 \\
\hline 1 & 3 & 1.88 & 1.62 & 1.41 & 1.40 & 1.52 & -0.36 \\
\hline 2 & 1 & 1.25 & 1.31 & 1.17 & 1.15 & 1.24 & -0.02 \\
\hline 2 & 2 & 1.30 & 1.17 & 1.12 & 1.26 & 1.37 & 0.06 \\
\hline 2 & 3 & 1.09 & 1.26 & 1.03 & 1.08 & 1.25 & 0.17 \\
\hline 3 & 1 & 0.87 & 0.96 & 0.90 & 0.84 & 0.61 & -0.26 \\
\hline 3 & 2 & 0.97 & 1.01 & 0.96 & 1.04 & 0.89 & -0.08 \\
\hline 3 & 3 & 0.85 & 1.02 & 1.23 & 1.14 & 1.09 & 0.24 \\
\hline \multicolumn{2}{|c|}{ average } & 1.39 & 1.37 & 1.27 & 1.28 & 1.27 & -0.13 \\
\hline
\end{tabular}

The last column is the difference between the 5 and 1 factor-loading portfolio returns. 